\title{
Systematic Identification of Pathogenic Streptomyces sp. AMCC400023 That Causes Common Scab and Genomic Analysis of Its Pathogenicity Island
}

\author{
Feiyang Liang, ${ }^{1}$ Rongshan Lin, ${ }^{1}$ Yaqian Yao, ${ }^{1}$ Yunli Xiao, ${ }^{2}$ Mingshuo Zhang, ${ }^{1}$ Chunyu Shi, ${ }^{3}$ \\ Xiaoli He, ${ }^{1}$ Bo Zhou, ${ }^{1,4, \dagger}$ and Bing Wang $1, \dagger$ \\ ${ }^{1}$ Department of Microbiology, College of Life Sciences, Shandong Agricultural University, Tai'an 271018, People's Republic of China \\ 2 Shandong Plant Protection Station \\ ${ }^{3}$ Agricultural College, Shandong Agricultural University, Tai'an 271018, People's Republic of China \\ ${ }^{4}$ National Engineering Laboratory for Efficient Utilization of Soil and Fertilizer Resources, Tai' an 271018, People's Republic of China \\ Accepted for publication 27 February 2019.
}

\begin{abstract}
Potato scab, a serious soilborne disease caused by Streptomyces spp., occurs in potato-growing areas worldwide and results in severe economic losses. In this paper, the pathogenicity of Streptomyces strain AMCC400023, isolated from potato scabs in Hebei Province, China, was verified systematically by the radish seedling test, the potato tuber slice assay, the potted back experiment, and the detection of phytotoxin thaxtomin A. Morphological, physiological, and biochemical characteristics were determined, and the 16S ribosomal RNA analyses of Streptomyces sp. AMCC400023 were carried out. To obtain the accurate taxonomic status of the pathogen strain, the whole genome was sequenced, and the phylogenetic tree among 31 Streptomyces genomes was formed. The average nucleotide identity (ANI) and in silico DNADNA hybridization (isDDH) were analyzed, and at the same time, the toxicity-related genes between Streptomyces sp. AMCC400023 and Streptomyces scabiei were compared, all based on the whole-genome

level. All of the data supported that, instead of a member of S. scabiei, test strain Streptomyces sp. AMCC400023 was a distinct phytopathogen of potato common scab, which had a relatively close relationship with S. scabiei while separating clearly from S. scabiei at least in the species level of taxonomic status. The complete pathogenicity island (PAI) composition of Streptomyces sp. AMCC400023 was identified, which contained a toxin region and a colonization region. It was conjectured that the PAI of Streptomyces sp. AMCC 400023 might be directly or indirectly acquired from S. scabiei $87-22$ by horizontal gene transfer, or at the very least, there was a very close homologous relationship between the two pathogens as indicated by a series of analyses, such as phylogenetic relationships among 31 Streptomyces species, ANI and isDDH analyses, PAI structure mapping, thaxtomin A synthetic gene cluster tree construction, and most important, the collinearity analysis at the genome level.
\end{abstract}

Members of the genus Streptomyces are gram-positive, filamentous actinomycetes that are distributed widely in nature, especially in soil, and they have genomes with very high $\mathrm{G}+\mathrm{C}$ content (Chapleau et al. 2016; Zhang et al. 2016a). Streptomyces species are capable of producing biologically active secondary metabolites, including multiple widely used antibiotics (Bentley et al. 2002; Bérdy 2005), and catabolic enzymes, enabling these bacteria to adapt well to a variety of complex soil environments (Bertram et al. 2004; Hodgson 2000). A small number of Streptomyces spp. are pathogens that can cause plant diseases (Loria et al. 2006). Potato scab is a global disease caused by Streptomyces species, causing pitted, raised, or superficial lesions on the surfaces of tuber crops, such as potatoes, beets, radishes, carrots, and peanuts, resulting in severe economic losses (Loria et al. 2006). S. scabiei was the first pathogen to be described in 1891, and it is distributed worldwide (Lambert and Loria 1989b). In the more than 100 years since, several pathogenic Streptomyces species have been reported. Among these species, Streptomyces turgidiscabies (Miyajima et al. 1998) and S. acidiscabies (Lambert and Loria 1989a) have been reported as separate pathogens in Japan and the United States. Currently, the best characterized scab-causing pathogens are

†Corresponding authors: B. Zhou; zhoubo2798@163.com, and B. Wang; bwang@sdau.edu.cn

Funding: This work was partially supported by National Key R\&D Program grants 2017YFD0201100 and 2017YFD0800200 and funding from Shandong Province Potato Industry Innovation Team Chief Expert Project grant SDAIT-16-01.

The author(s) declare no conflict of interest.

C 2019 The American Phytopathological Society
S. scabiei, S. turgidiscabies, S. acidiscabies, and Streptomyces ipomoeae (Loria et al. 2008). In addition to the four main pathogenic bacteria mentioned above, there are other reported pathogens that cause common scab, namely S. europaeiscabiei, S. stelliscabiei, S. luridiscabiei, S. puniciscabiei, S. niveiscabiei, S. reticuliscabiei, S. caviscabiei, and S. bottropensis (Bouchek-Mechiche et al. 2000; Goyer et al. 1996; Park et al. 2003; Zhou et al. 2016).

The major causative agent of potato scab is a family of toxins known as thaxtomins (Loria et al. 2006). Thaxtomins are substances with a 4-nitroindol-3-yl-2,5-dioxopiperazine scaffold (Lerat et al. 2009). A total of 11 thaxtomin family members have been isolated. These thaxtomins are distinguished by the presence or absence of $\mathrm{N}$-methyl or hydroxyl groups (Bignell et al. 2010a). Among these compounds, thaxtomin A (ThxA), a nitrated 2,5-diketopiperazine, is the main toxin form produced by $S$. scabiei, S. acidiscabies, and S. turgidiscabies (Healy et al. 2000; King et al. 1989; Lawrence et al. 1990), whereas the toxin produced by the pathogen S. ipomoeae is thaxtomin C, a nonhydroxylated homolog of ThxA (King and Lawrence 1994). Thaxtomins induce a series of changes in plant host phenotypes, which can reduce the crystalline cellulose content in the cell walls of plants; affect the expression of genes associated with cell wall synthesis; cause cell hypertrophy, root growth retardation, and $\mathrm{Ca}^{2+}$ and $\mathrm{H}^{+}$influx in plants; and result in tissue necrosis and programmed cell death (Bignell et al. 2010a; Johnson et al. 2007; Loria et al. 2008). The necl gene encodes a secreted protein that is a newly identified type of toxic protein. This protein is necessary for the colonization of plant hosts by pathogenic bacteria. The main function of this protein might be to inhibit the defensive response of plants during pathogenic infection (Bignell et al. 2010a). The tomA gene encodes a homolog of tomatinase (Bignell et al. 2010a), which is mainly found in 
phytopathogenic fungi, and the target of this protein is an antibiotic alkaloid that participates in detoxification during pathogenic infection of the host (Braun et al. 2017). Nec1 and TomA are not required for pathogenicity, but these proteins may play an important role during the infection process (Joshi et al. 2007a; Seipke and Loria 2008). S. turgidiscabies also contains the fas operon, which is adjacent to the thaxtomin synthesis cluster and homologous to the fas operon in Rhodococcus fascians (Joshi and Loria 2007). Fas proteins mediate the synthesis and modification of cytokinins, which may be closely associated with the types of lesions caused by pathogens (Pertry et al. 2010).

A 674-kb pathogenicity island (PAI) was discovered in S. turgidiscabies in 2005, and it was the first PAI identified in gram-positive bacteria (Huguet-Tapia et al. 2014; Kers et al. 2005). In S. turgidiscabies Car8, the PAI harbors four virulence factors: the ThxA synthetic gene cluster, necl, tomA, and the fas operon (Huguet-Tapia et al. 2011; Kers et al. 2005). However, in S. scabiei and $S$. acidiscabies, the PAI contains all of the virulence factors except the fas operon, and the PAI is divided into two regions, the toxin region (TR) and the colonization region (CR), which are far apart in the linear chromosome of Streptomyces spp. In S. scabiei $87-22$, these two regions are $4.9 \mathrm{Mb}$ apart (Lerat et al. 2009), and the TR is further separated into two subregions (TR1 and TR2) by attachment (att) sites (Chapleau et al. 2016). TR1 contains the ThxA biosynthetic gene cluster, and TR2 includes an integrative and conjugative element (ICE) (Chapleau et al. 2016), whereas the CR contains only the necl and tomA genes (Lerat et al. 2009).

Horizontal gene transfer (HGT) is a method by which bacteria share genetic material, promoting bacterial evolution and enabling the rapid emergence of new pathogenic species (Eggers et al. 2016). Thus, it is speculated that the major causative genes of the scab caused by streptomycetes form ICEs for mobilization (Chapleau et al. 2016). Most ICEs are transferred as single-stranded DNA, whereas conjugative elements are transferred as double-stranded DNA in streptomycetes and related actinomycetes (Huguet-Tapia et al. 2014). ICEs are specifically excised from host chromosomes to form extrachromosomal circulatory elements, which can then be conjugated into recipient cells and specifically integrated into the chromosomes of recipient cells (Bordeleau et al. 2012; Chapleau et al. 2016). Therefore, the mobilization of PAIs is thought to be the main driving force for the evolution of phytopathogenic streptomycetes (Loria et al. 2006).

Before assessing the evolution of PAIs in pathogenic Streptomyces species, a clear understanding of the phylogenetic relationship between pathogenic Streptomyces species and nonpathogenic Streptomyces species is crucial; 16S ribosomal RNA (rRNA) sequence analysis is the standard method for bacterial identification (Kreuze et al. 1999; Zhang et al. 2016a), but the high similarity of the 16S rRNA sequences of Streptomyces spp. limits the application of this identification method for these bacteria (Labeda et al. 2012). To successfully carry out accurate identification of Streptomyces species, multilocus sequence analysis has been rapidly developed (Guo et al. 2008). Multiple internal fragments of various enzyme-encoding genes, such as ATP synthase F1 (beta subunit; atpD), DNA gyrase (beta subunit; $g y r B$ ), recombinase A (recA), RNA polymerase (beta subunit; rpoB), and tryptophan synthase (beta subunit; $\operatorname{trp} B$ ), can be used to identify closely related Streptomyces species (Guo et al. 2008). In addition, specific primers for different strains can be designed based on the variable regions of the 16S rRNA gene sequences of pathogenic strains (Wanner 2006), such as S. scabiei, S. europaeiscabiei, S. stelliscabiei, S. bottropensis, S. acidiscabies, S. turgidiscabies, and Streptomyces aureofaciens. Therefore, polymerase chain reaction (PCR) amplification of target fragments with specific primers is used to rapidly identify and isolate pathogenic Streptomyces spp. (Dees et al. 2013; Leiminger et al. 2013).

In this study, the systematic pathogenicity verification and molecular identification of the pathogenic strain Streptomyces sp.
AMCC400023, which was isolated and stored in our laboratory, was carried out. Subsequently, whole-genome analysis was performed to determine the compositional differences and phylogenetic relationships between the test strain and related pathogenic strains. Simultaneously, the structure composition as well as the possible evolution development of gene island PAI are also discussed here at the genome level.

\section{MATERIALS AND METHODS}

Bacterial strains and culture conditions. The Streptomyces sp. AMCC400023 strain used in this study was isolated from potato scabs in the Dagong Village $\left(39^{\circ} 31^{\prime} 47^{\prime \prime} \mathrm{N} ; 118^{\circ} 14^{\prime} 36^{\prime \prime} \mathrm{E}\right)$, Daodi Town, Lunan District, Tangshan City, Hebei Province, China. All Streptomyces strains were grown at $28^{\circ} \mathrm{C}$ using oat agar (OMA) medium (International Streptomyces Project 3 [ISP 3]) or Gause's No. 1 medium. All liquid cultures (NA medium) were shaken at $250 \mathrm{rpm}$ at $28^{\circ} \mathrm{C}$.

DNA extraction. According to the method described by AbdelRahman et al. (2012), the AMCC400023 strain was inoculated into YEME liquid medium and cultured at $28^{\circ} \mathrm{C}$ for $48 \mathrm{~h}$. The DNA from the Streptomyces strain was extracted and dissolved in TE buffer, and the purity was determined. The DNA was then stored at $-20^{\circ} \mathrm{C}$ (Abdel-Rahman et al. 2012).

Pathogenicity-associated genes identification. The sequences of the primer pairs used for PCR are shown in Table 1. PCR amplification was conducted in a $25-\mu 1$ reaction system that contained $12.5 \mu \mathrm{l}$ of $2 \times$ TransStart FastPfu Fly PCR SuperMix (TaKaRa), $1 \mu \mathrm{l}$ of each primer, $0.5 \mu \mathrm{l}$ of DNA template, and MilliQ water to bring the volume to $25 \mu \mathrm{l}$. The amplified product was detected by agarose gel (1\%) electrophoresis.

ThxA production. The mycelial suspensions $(10 \mu \mathrm{l})$ of Streptomyces sp. AMCC400023 and S. scabiei NRRL B-16523 strain were inoculated into $3 \times 100 \mathrm{ml}$ of OBB medium in a $250-\mathrm{ml}$ flask and shaken at $28^{\circ} \mathrm{C}$ for 6 days $(200 \mathrm{rpm})$. After culturing for 6 days, the medium was centrifuged at $8,000 \mathrm{rpm}$ for $20 \mathrm{~min}$, and the supernatant was collected. The supernatant was extracted twice with an equal volume of ethyl acetate, and after rotary evaporation, the residue was dissolved in $2 \mathrm{ml}$ of acetonitrile to get the ThxA solution. The solution was filtered through a $0.2-\mu \mathrm{m}$ polytetrafluoroethylene filter and analyzed using LC-MS/MS (4000 Q TRAP; AB SCIEX USA) with a $0.4 \mathrm{ml} / \mathrm{min}$ flow rate of an isocratic mobile phase of 40:60 acetonitrile:water. ThxA was detected according to the method described previously (Leclerc et al. 2017). The mycelia of the culture strains were dried and weighed as a measue of Streptomyces strains. The average ThxA production of Streptomyces sp. AMCC400023 strain based on dry cell weight was set to $100 \%$. The average ThxA production of S. scabiei NRRL B-16523 based on dry cell weight was relatively obtained from the value of Streptomyces sp. AMCC400023. All experiments were repeated three times with different biological samples of Streptomyces strains.

Tuber slice assay and radish seedling test. In the potato tuber slice assay, according to the method described by Loria et al. (1995), a healthy potato tuber slice was selected to inoculate pathogen-containing agar blocks in the dark at $25^{\circ} \mathrm{C}$ (Loria et al. 1995). After 10 days, the ratio of necrosis area to inoculum area was measured (Hao et al. 2009). The above test was repeated three times.

The in vitro radish seedling test was performed as described previously (Bignell et al. 2010b); however, the Burpee White variety was replaced with the South Korean variety of radish seeds. Mycelial suspensions were used to inoculate three similarly sized newly germinated radish seedlings, and an equal amount of noninoculated pathogenic culture medium was used as a blank control. The percentage of inhibition of radish sprout growth was used as an indicator of pathogenicity (Leiner et al. 1996). This experiment was repeated three times for each sample.

Potted back test of pathogenicity. Healthy potato tubers of variety Dutch 15 were selected for germination and then sown. The 
spore suspension was inoculated during the expansion period so that the final concentration of the pathogenic Streptomyces strain in the substrate was $10^{6} \mathrm{cfu} / \mathrm{cm}^{3}$. Each treatment was repeated in five pots. A sample that was not treated with the pathogen was used as a blank control. After 90 days of cultivation, the disease index was calculated, and DNA was extracted from the lesions for PCR-based detection. Disease index $($ percentage $)=\Sigma($ incidence level $\times$ number of corresponding grades $) /($ the highest incidence level $\times$ total number in this survey) $\times 100$ (Hao et al. 2009).

Morphological, physiological, and biochemical characteristics of pathogenic Streptomyces species. The morphological characteristics of pathogenic Streptomyces sp. AMCC400023, such as spore chains, spore color, and soluble pigments, were evaluated using the methods described in the ISP (Shirling and Gotlieb 1966). The colonies and spores were observed on OMA medium for 14 days at $14^{\circ} \mathrm{C}$, and the observations were recorded.

The carbon source utilization, nitrogen source utilization, and sensitivity of the pathogenic Streptomyces sp. AMCC400023 were measured as described previously (Lambert and Loria 1989b; Shirling and Gotlieb 1966).

Cloning and sequencing of the 16S rRNA gene. After the DNA of Streptomyces sp. AMCC400023 was extracted, the 16S rDNA gene sequence was amplified using the universal Streptomyces primer pair PA/PH (Edwards et al. 1989). The 16S rRNA sequences were compared by BLAST, and a phylogenetic tree was constructed using the neighbor-joining algorithm with Mega7.0.14 software.

De novo genome sequencing and assembly. We sequenced whole genome of the Streptomyces sp. AMCC400023 strain using PacBio RSII third generation sequencing technology. For the original genomic data, the hierarchical genome assembly process algorithm was used for genome assembly. Gene discovery and annotation were performed using the Subsystems Technology (RAST) server (Aziz et al. 2008) and BLAST comparison tools.

Ortholog retrieval and single-copy cluster search. To construct a phylogenetic tree, Brevibacillus laterosporus AMCC100017 was used as the outgroup. The protein-coding sequences of 31 Streptomyces strains (Table 2) and one outgroup were used for the identification of homologous clusters by OrthoMCLv2.0.9 (Li et al. 2003). Clustering by OrthoMCL software was performed by BLAST similarity comparison with default settings. Single-copy homologous genes in the genome were selected as potential markers for phylogenetic analysis.

Gene alignment and filtration criteria. To minimize the low-quality fragments in the comparative analysis, various filtration standards were used as described previously (Zhang et al. 2016a). Multiple sequence alignments were performed for the genome of each strain using MUSCLEv3.8.31, and the calculations were compared by using default settings (Edgar 2004a, b).
Phylogenetic evaluation by the maximum likelihood method. Nucleotide sequence alignments of the genes were performed using the maximum likelihood method on the RAxMLv8.2.11 platform (Stamatakis 2014; Zhang et al. 2016a). The calculation parameters were as follows: -fa -x 12345 -p 12345 -\# 100 -m PROTGAMMALGX. To estimate the reliability of the tree, 1,000 self-examination values were adopted.

Average nucleotide identity and in silico DNA-DNA hybridization analyses. Average nucleotide identity (ANI) analysis of the whole genome was performed using the methods suggested by Richter and Rossellómóra (2009). Paired ANI values were obtained by using nucmer (Delcher et al. 2002) with script calculate_ani.py (https://github.com/widdowquinn/scripts/blob/ master/bioinformatics/calculate_ani.py).

In silico DNA-DNA hybridization (isDDH) was calculated using the genome-to-genome distance calculator (GGDC) (Auch et al. 2010; Meier-Kolthoff et al. 2013). The contig files were uploaded to the GGDC2.0 web server (http://ggdc.dsmz.de/distcalc2.php), where the isDDH calculations were performed using only Formula 2.

Gene collinearity analysis. The genomic sequences of selected major pathogens were obtained from the NCBI database. With the Streptomyces sp. AMCC400023 strain as a reference strain, collinearity analysis was performed by MCScanXv 0.8 (Wang et al. 2012). The algorithm parameters were set to default values.

Identification of toxin genes in pathogenic Streptomyces species. Using the whole-genome sequences of S. scabiei 87-22 and Streptomyces sp. AMCC400023, BLAST alignments were performed with the Virulence Factors of Pathogenic Bacteria Database to identify all pathogenicity-related genes in these two pathogens.

\section{RESULTS}

Pathogenicity verification of Streptomyces sp. AMCC400023. Streptomyces sp. AMCC400023 that causes potato scab was isolated from a diseased potato sample in the Dagong Village $\left(39^{\circ} 31^{\prime} 47^{\prime \prime} \mathrm{N} ; 118^{\circ} 14^{\prime} 36^{\prime \prime}\right)$, Daodi Town, Lunan District, Tangshan City, Hebei Province, China. The potato tuber slice assay and the radish seedling test were conducted to verify the pathogenicity of this strain, and the results are shown in Figure 1. On treatment, Streptomyces sp. AMCC400023 exhibited similar symptoms as the positive control S. scabiei (type strain NRRL B-16523), and the pathogenic test results are shown in Table 3. A potted back experiment of isolate AMCC400023 was also conducted to verify the pathogenicity of this strain. Potatoes were harvested after cultivation for 90 days, and the results showed that

TABLE 1. Primer sequences used in the experiments

\begin{tabular}{|c|c|c|c|}
\hline Amplified gene and primer & Primer sequence & Fragment size (bp) & Reference \\
\hline \multicolumn{4}{|l|}{$\overline{16 S \text { rRNA }}{ }^{a}$} \\
\hline PA & 5'-TTTGATCCTGGCTCAG-3' & 1,535 & Edwards et al. 1989 \\
\hline PH & 5'-AAGGAGGTGATCCAGCCGCA-3' & & \\
\hline ITS-L & 5'-GTCAAGTCATCATGCCCCTT-3' & 650 & Song et al. 2004 \\
\hline ITS-R & 5'-AAACTTGGCCACAGATGCTC-3' & & \\
\hline \multicolumn{4}{|c|}{ 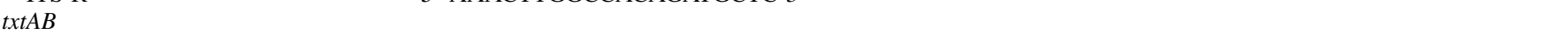 } \\
\hline txtAB1 & 5'-CCACCAGGACCTGCTCTTC-3' & 385 & Wanner 2006 \\
\hline $\mathrm{Nf}$ & 5'-ATGAGCGCGAACGGAAGCCCCGGA-3' & 700 & Bukhalid et al. 2002 \\
\hline $\mathrm{Nr}$ & 5'-GCAGGTCGTCACGAAGGATCG-3' & & \\
\hline \multicolumn{4}{|c|}{ (6) } \\
\hline Tom3 & 5'-GAGGCGTTGGTGGAGTTCTA-3' & 392 & Wanner 2006 \\
\hline Tom4 & 5'-TTGGGGTTGTACTCCTCGTC-3' & & \\
\hline
\end{tabular}

a rRNA, ribosomal RNA. 
inoculation with the AMCC400023 strain caused typical scab lesions on the potato surfaces (Fig. 1I) with an incidence rate of $42.9 \%$ (Table 3).

ThxA production by Streptomyces sp. AMCC400023 and S. scabiei NRRL B-16523 was analyzed in OBB medium, which is a complex medium for inducing ThxA biosynthesis (Wach et al. 2007). The two test strains were able to synthesize ThxA as expected by LC-MS/MS analysis (Fig. 2), whereas the amount of ThxA synthesized by S. scabiei NRRL B-16523 strain was significantly higher than that by Streptomyces sp. AMCC400023.

Morphological, physiological, and biochemical characteristics of Streptomyces sp. AMCC400023. Streptomyces sp. AMCC400023 was cultured in OMA and ISP medium at $28^{\circ} \mathrm{C}$ for 14 days. After being cultured for 14 days, Streptomyces sp. AMCC400023 formed abundant endophytic and aerial hypha. The mature spores were gray and columnar, and the spore chains were loose spiral. The aerial hypha were gray to white in different media, and the substrate mycelium was gray to yellow or yellowish brown on different media. Soluble pigments were produced on ISP 6 medium. Streptomyces sp. AMCC400023 produced melanin on tyrosine medium and could utilize D-glucose, D-mannitol, raffinose, rhamnose, sucrose, D-xylose, inositol, and other sugars. In addition, L-histidine and L-methionine in nitrogen source could also be utilized by this strain. The specific characteristics of the colony morphology, microscopic morphology, and scanning electron micrographs are shown in Figure 3 and Table 4, and the physiological and biochemical characteristic results of Streptomyces sp. AMCC400023 compared with those of related pathogenic streptomycetes from other studies are shown in Table 5.

16S rRNA phylogenetic tree of Streptomyces sp. AMCC400023 and related pathogenic streptomycetes. After DNA extraction, the 16S rDNA gene sequence of Streptomyces sp. AMCC400023 was amplified by PCR and sequenced (GenBank accession number KU189257). Subsequently, whole-genome sequencing of this strain was performed, and a full sequence was obtained. There were six $16 \mathrm{~S}$ rRNA gene sequences in the genome, and one of them was chosen to construct a phylogenetic tree. The phylogenetic tree showed that the 16S rRNA gene sequence amplified by $16 \mathrm{~S}$ rDNA and the $16 \mathrm{~S}$ rRNA gene sequences present in the genome of the AMCC400023 strain were closely related to the type species S. bottropensis ATCC25435 (Fig. 4). Considering the complicated situation in the identification of streptomycetes, more work should be carried out to obtain the accurate taxonomic status.

Phylogenetic analysis and genomic similarity analysis between pathogenic and nonpathogenic Streptomyces species. To accurately predict the phylogenetic relationships of strain AMCC400023 (GenBank complete genome accession number CP024989) with those species among the genus Streptomyces, 31 Streptomyces strains, including pathogenic and nonpathogenic species, were selected from the NCBI database for comprehensive phylogenetic analysis. A total of 1,104 single-copy homologous gene clusters from these 31 strains and 1 outgroup strain (B. laterosporus AMCC100017) were first screened using OrthoMCLv2.0.9 (Li et al. 2003). The nucleotide sequences of these 1,104 single-copy gene groups were matched to eliminate mismatched sites, and 500 orthologous groups remained. The remaining genes were subjected to linkage analysis, and the maximum likelihood method was used to predict the phylogenetic relationships among the 31 Streptomyces strains.

In the phylogenetic tree in Figure 5, pathogenic Streptomyces strains were divided into three major branches. The main pathogen $S$. acidiscabies represented one branch, and $S$. turgidiscabies represented one branch and was located in the farthest position. Interestingly, S. scabiei, S. europaeiscabiei, S. bottropensis

TABLE 2. Genomic statistical data of pathogenic and nonpathogenic Streptomyces species

\begin{tabular}{|c|c|c|c|c|c|c|c|c|}
\hline Species & Strain name & $\begin{array}{l}\text { Genome } \\
\text { status }\end{array}$ & $\begin{array}{l}\text { Contig } \\
\text { number }\end{array}$ & $\begin{array}{l}\text { Contig } \\
\mathrm{N}^{2} 0^{\mathrm{a}} \\
\text { (kb) }\end{array}$ & $\begin{array}{c}\text { Genome } \\
\text { size } \\
(\mathrm{Mb})\end{array}$ & $\begin{array}{l}\text { Geographic } \\
\text { location }\end{array}$ & $\begin{array}{l}\text { GenBank assembly } \\
\text { accession number }\end{array}$ & Source or reference \\
\hline Streptomyces sp. & AMCC400023 & Complete & & & 10.7 & Hebei, China & СР024989 & This article \\
\hline S. bottropensis & ATCC25435 & Draft & 109 & 195.2 & 8.9 & Unknown & AOCF00000000.1 & \\
\hline S. europaeiscabiei & $96-14$ & Draft & 931 & 21.2 & 10.5 & Australia & GCA_001550375.1 & Zhang et al. 2016a \\
\hline S. europaeiscabiei & $89-04$ & Draft & 1,080 & 17.7 & 10.5 & Alaska, U.S.A. & GCA_001550325.1 & Zhang et al. $2016 \mathrm{a}$ \\
\hline S. europaeiscabiei & NRRL B-24443 & Draft & 1,056 & 16.4 & 10 & Le Rhue, France & GCA_000988945.1 & Labeda et al. 2012 \\
\hline S. stelliscabiei & NRRL B-24447 & Draft & 991 & 19.0 & 10.0 & France & GCA_001008135.1 & Labeda et al. 2012 \\
\hline S. scabiei & $87-22$ & Complete & & & 10.1 & Wisconsin, U.S.A. & GCA_000091305.1 & Bignell et al. 2010a, b \\
\hline S. scabiei & $95-18$ & Draft & 1,798 & 10.6 & 10.5 & South Africa & GCA_001550225.1 & Zhang et al. 2016a \\
\hline S. scabiei & $84-34$ & Draft & 1,650 & 10.9 & 10.0 & $\begin{array}{l}\text { Upstate New } \\
\text { York, U.S.A. }\end{array}$ & GCA_001550245.1 & Zhang et al. $2016 \mathrm{a}$ \\
\hline S. scabiei & NRRL B-16523 & Draft & 1,091 & 15.1 & 9.8 & $\begin{array}{l}\text { Central New } \\
\text { York, U.S.A. }\end{array}$ & GCA_001005405.1 & Labeda et al. 2012 \\
\hline S. scabiei & $84-232$ & Draft & 1,464 & 12.6 & 9.8 & $\begin{array}{l}\text { West Virginia, } \\
\text { U.S.A. }\end{array}$ & GCA_001572115.1 & Zhang et al. $2016 \mathrm{a}$ \\
\hline S. scabiei & $96-08$ & Draft & 1,374 & 10.6 & 11.2 & Alberta, Canada & GCA_001550235.1 & Zhang et al. 2016a \\
\hline S. scabiei & NRRL B-24093 & Draft & 1,675 & 11.5 & 9.9 & Egypt & GCA_002155765.1 & Labeda et al. 2012 \\
\hline S. scabiei & NRRL B-2801 & Draft & 1,521 & 14.1 & 10.3 & $\begin{array}{l}\text { Presque Isle, } \\
\text { ME, U.S.A. }\end{array}$ & GCA_002155725.1 & Labeda et al. 2012 \\
\hline S. scabiei & $96-06$ & Draft & 1,173 & 9.9 & 9.0 & Ontario, Canada & GCA_001579685.1 & Zhang et al. 2016a \\
\hline Streptomyces sp. & $96-12$ & Draft & 1,875 & 8.7 & 10.1 & Egypt & GCA_001550315.1 & Zhang et al. $2016 \mathrm{a}$ \\
\hline S. ipomoeae & $91-03$ & Draft & 687 & 26.4 & 10.4 & U.S.A. & GCA_000317595.1 & Huguet-Tapia et al. 2014 \\
\hline S. acidiscabies & 84-104 & Draft & 244 & 113.4 & 11.0 & $\begin{array}{l}\text { Upstate New } \\
\text { York, U.S.A. }\end{array}$ & GCA_000242715.2 & Huguet-Tapia et al. 2011 \\
\hline S. acidiscabies & $98-48$ & Draft & 983 & 20.3 & 10.6 & Saga, Japan & LYDS00000000 & Zhang et al. 2016b \\
\hline S. acidiscabies & $98-49$ & Draft & 1,211 & 16.5 & 10.2 & Saga, Japan & LYDT00000000 & Zhang et al. $2016 \mathrm{~b}$ \\
\hline S. niveiscabiei & NRRL B-24457 & Draft & 1,568 & 10.1 & 9.5 & Jeju, South Korea & GCA_001419795.1 & Labeda et al. 2012 \\
\hline S. diastatochromogenes & ATCC 12309 & Draft & 1,280 & 18.6 & 12.3 & Japan & GCA_001550305.1 & Zhang et al. 2016a \\
\hline S. galbus & КССМ 41354 & Draft & 104 & 24.2 & 10.1 & Korea & GCA_000772895.1 & \\
\hline S. coelicolor & $\mathrm{A} 3(2)$ & Complete & & & 9.1 & England & GCA_000203835.1 & \\
\hline S. turgidiscabies & Car8 & Draft & 692 & 27.5 & 10.8 & Japan & GCA_000331005.1 & Huguet-Tapia et al. 2011 \\
\hline
\end{tabular}

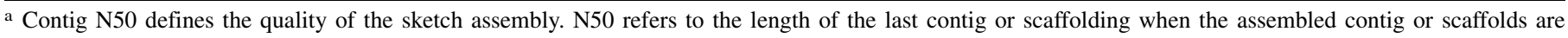
arranged in descending order and their cumulative length just exceeds $50 \%$ of the total length of the entire assembly sequence. For the complete genome, no N50 is available. 
ATCC25435, and Streptomyces sp. AMCC400023, each representing a small branch, were clustered into one large branch. The test strain Streptomyces sp. AMCC400023 exhibited a relatively close relationship with $S$. scabiei in the phylogenetic tree.

ANI and isDDH analyses among Streptomyces phytopathogens at the genomic level. The ANI and isDDH values and core genome-based phylogenetic analysis showed that Streptomyces sp. AMCC400023 was clustered with the Streptomyces sp. 96-12 and S. scabiei NRRL B-24093 strains instead of with the $S$. bottropensis ATCC25435 strain, although the similarity between the $16 \mathrm{~S}$ rRNA sequences of Streptomyces sp.
AMCC400023 and S. bottropensis ATCC25435 reached 100\%. At the same time, Streptomyces sp. AMCC400023 could not be classified into a member of $S$. scabiei owing to its ANI and isDDH values as well as the genome core tree in Figure 6 . This result indicated that Streptomyces sp. AMCC400023 might be a distinct pathogenic Streptomyces species.

PAI structure and composition of Streptomyces sp. AMCC400023. Gene composition analysis of Streptomyces sp. AMCC400023 PAI was performed by a hidden Markov model (Punta et al. 2011), and a PAI structure plot was then constructed (Fig. 7). The results showed that TR1 contained 10 open reading
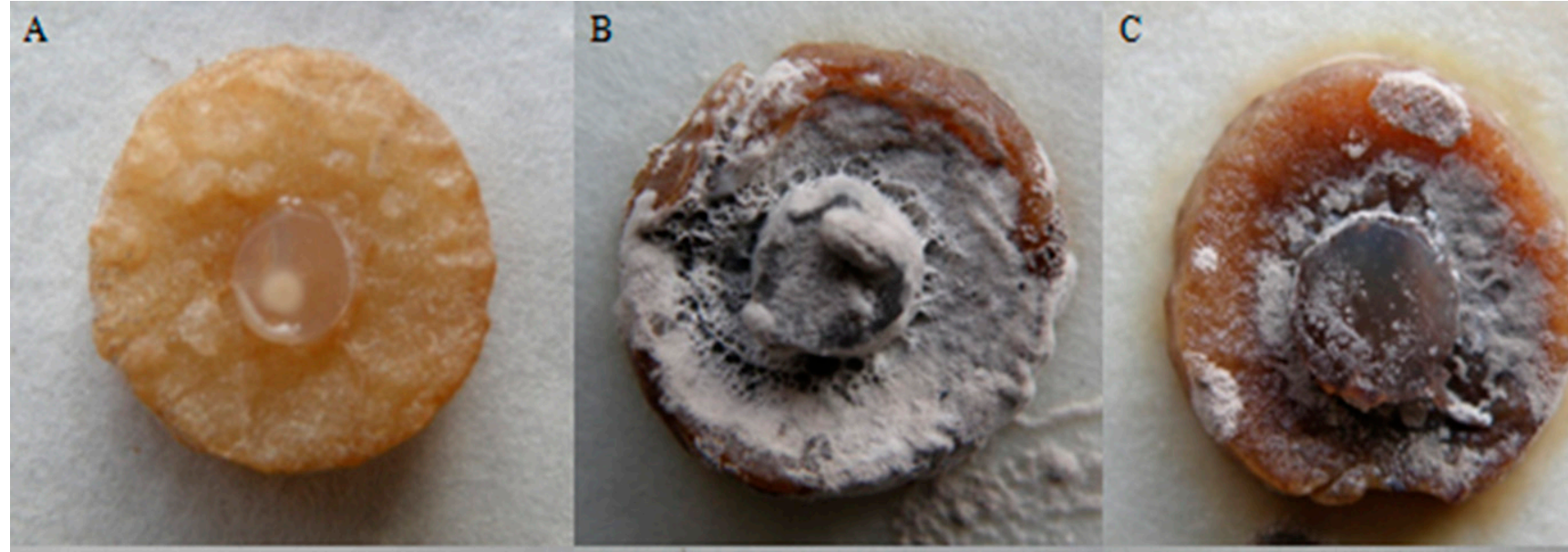

$\mathrm{D}$

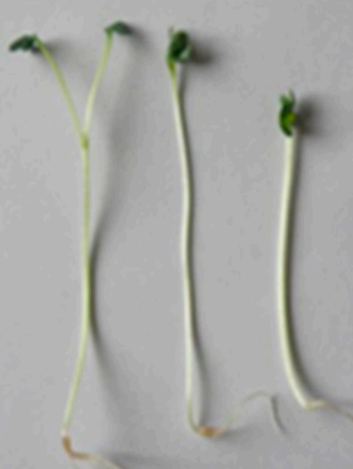

E

F
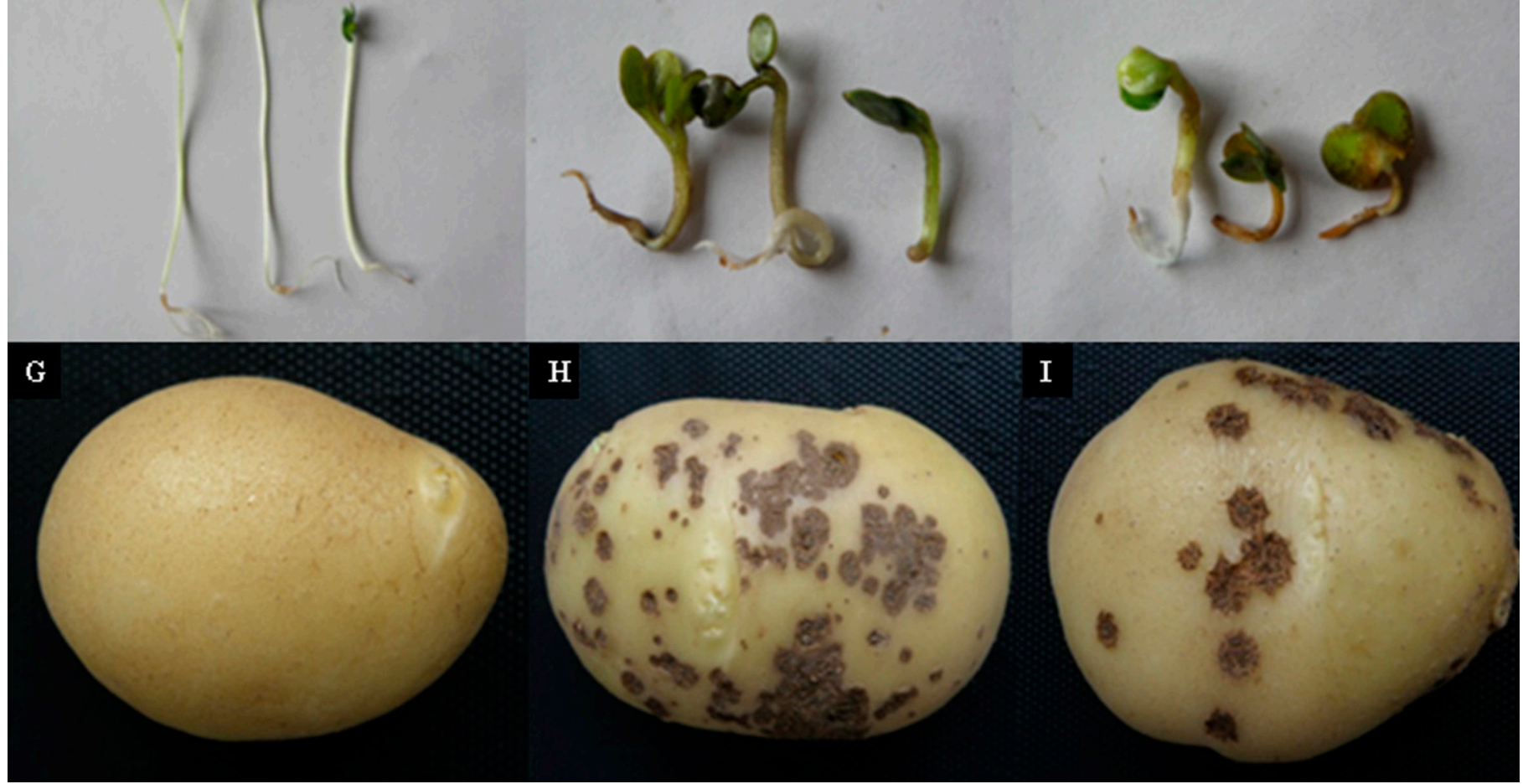

Fig. 1. Pathogenicity verification of Streptomyces sp. AMCC400023. A, B, and C, Potato tuber slice assay, D, E, and F, radish seedling test, and G, H, and I, potted back experiment. A, D, and G, Blank control without pathogen inoculation. B, E, and H, Inoculated with positive control Streptomyces scabiei NRRL B-16523. C, F, and I, Inoculated with Streptomyces sp. AMCC400023.

TABLE 3. Pathogenic test results of Streptomyces sp. AMCC400023

\begin{tabular}{|c|c|c|c|}
\hline Strain & Potato tuber slice assay, $\%$ & Radish seedling inhibition rate, $\%$ & Pot experiment disease index, $\%$ \\
\hline S. scabiei NRRL B-16523 & 100 & 88.2 & 42.9 \\
\hline Streptomyces sp. AMCC400023 & 96 & 84.7 & 37.5 \\
\hline
\end{tabular}


frames (ORFs). These 10 ORFs included the thaxtomin biosynthetic gene cluster and other genes encoding putative proteins, whereas there were no genes associated with ICEs in this region. TR2 contained 151 ORFs, including lantibiotic synthesis gene clusters, site-specific integrases, and recombination directionality factors. Related genes for conjugative transfer were present in this region, and a locus with replication function was also identified in this region. There were 80 ORFs in the CR region, including the necl gene, which encoded a necrotic protein, and the tom $A$ gene, which encoded tomatinase. In this region, there were many genes that were involved in sugar metabolism. However, the gene encoding the IS110 family transposase was deleted in TR2 of Streptomyces sp. AMCC400023. We also found that the Streptomyces sp. AMCC400023 strain contained genes encoding NADP oxidoreductase, an HxlR family transcriptional regulator, and the peptidase S12 upstream of the CR. These three genes were not found in S. scabiei.

Phylogenetic comparison of the ThxA biosynthetic gene cluster and the core genome. The TR in the PAI, containing the

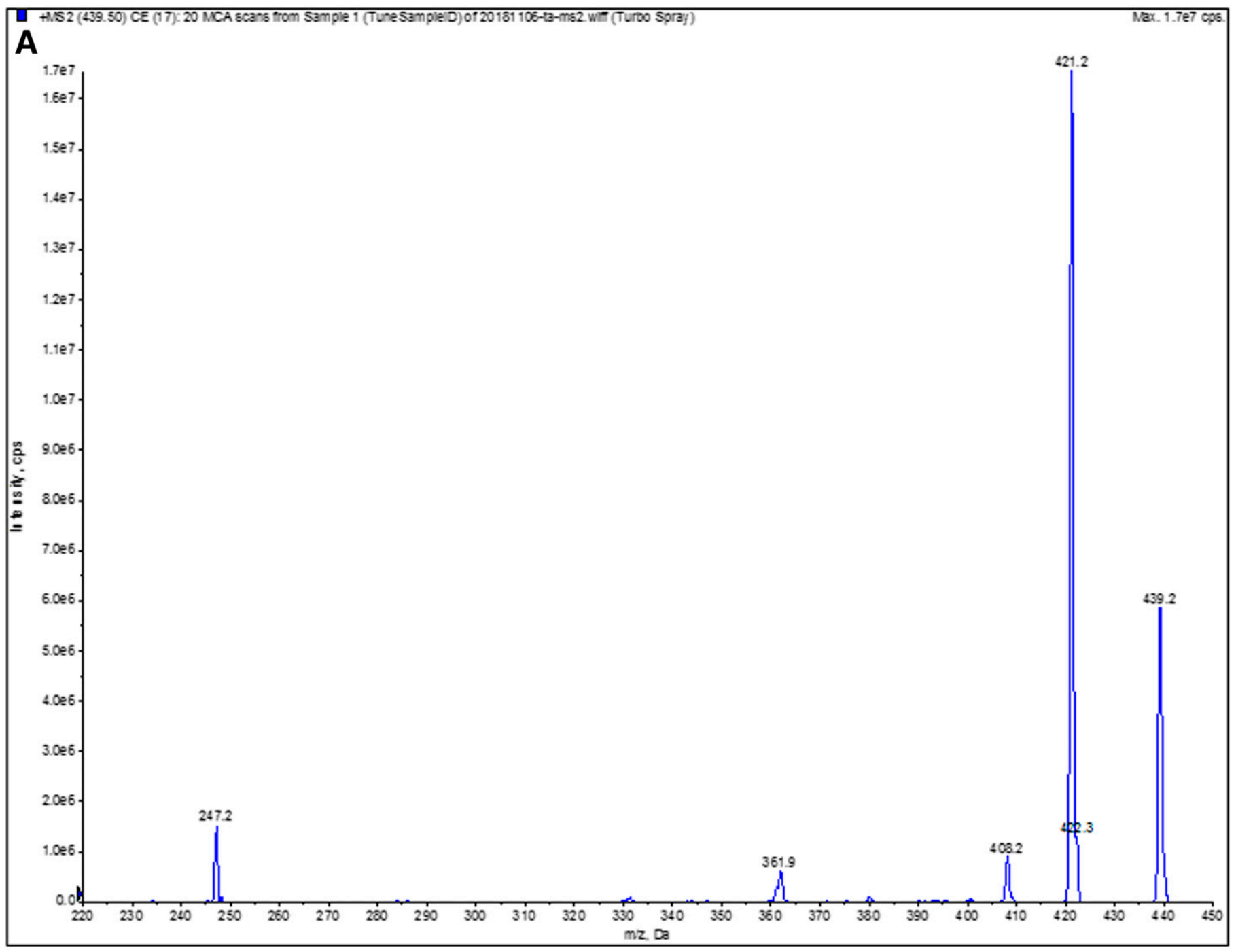

B

Streptomyces sp. AMCC400023

S. scabiei NRRL B-16523

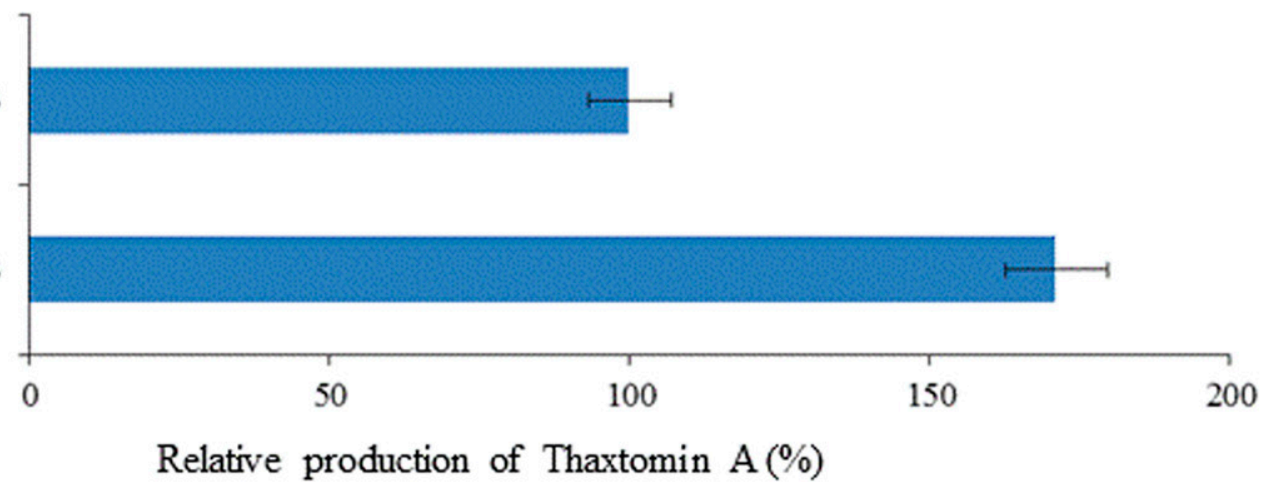

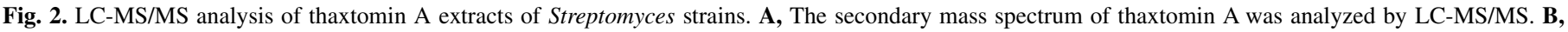

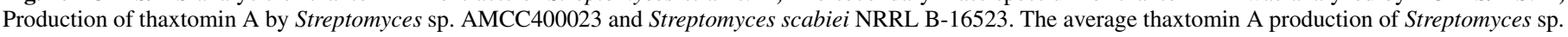

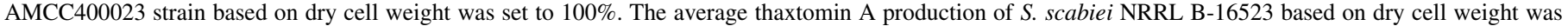
relatively obtained from the value of Streptomyces sp. AMCC400023. The error bars represented the standard deviations of the mean. 
ThxA synthetic gene cluster, could participate in conjugative transfer, leading to the formation of novel Streptomyces spp. To explore the evolutionary origin of the PAI in Streptomyces sp. AMCC400023, the phylogenetic tree of ThxA was constructed using $t x t A, t x t B, t x t C, t x t D, t x t E, t x t H$, and $t x t R$ from the ThxA biosynthetic gene cluster (Fig. 6). In the ThxA phylogenetic tree, Streptomyces sp. AMCC400023 clustered closely with $S$. acidiscabies and $S$. scabiei, indicating that the ThxA synthetic gene cluster in the genomes of these strains was highly similar and homologous. In contrast, these strains were far apart in the tree for the core genome. Therefore, we hypothesized that Streptomyces species Streptomyces sp. AMCC400023, S. acidiscabies, and S. scabiei harbored the same ThxA synthetic gene cluster and that they all had the same evolutionary origin and were disseminated by HGT. Although S. europaeiscabiei and S. stelliscabiei harbored the same ThxA synthetic gene cluster, $S$. turgidiscabies was located separately in a far position.

Collinearity analysis of different pathogenic Streptomyces species. In the collinearity analysis, Streptomyces sp. AMCC400023 was used as a reference strain, and the main and well-studied pathogens S. scabiei 87-22, S. scabiei NRRL B-24093, type strain S. scabiei NRRL B-16523, S. scabiei NRRL B-2801, S. acidiscabies 84-104, S. turgidiscabies Car8, and S. europaeiscabiei NRRL B-24443 were selected for this analysis (Fig. 8).

In the collinearity map, Streptomyces sp. AMCC400023 shared a large number of similar genes with those related pathogenic streptomycetes, and most of them were genes located in PAI. Consensus genes between Streptomyces sp. AMCC400023 and S. turgidiscabies Car8 as well as S. europaeiscabiei NRRL B-24443 all located in the area of 0 to $5 \mathrm{M}$ bp of genome size, whereas the consensus genes between Streptomyces sp. AMCC400023 and S. acidiscabies 84-104, type strain S. scabiei NRRL B-16523, S. scabiei NRRL B-24093, and S. scabiei NRRL B-2801, all located near the position of 0,3 , and $10 \mathrm{M}$ of genome size. Interestingly, consensus sequence between Streptomyces sp. AMCC400023 and S. scabiei 87-22 was very dense, which indicated a similar and close gene arrangement. These homologous sequences or in another words, these homologous genes were a clear gene transfer proof, although we could not distinguish the exact gene transfer direction.

Toxicity-associated gene analysis between Streptomyces sp. AMCC400023 and S. scabiei 87-22. A comparative genomic analysis in the Virulence Factors of Pathogenic Bacteria Database was performed between Streptomyces sp. AMCC400023 and the well-studied S. scabiei 87-22. In this analysis, besides 69 common toxicity-associated genes, 60 unique virulence-associated genes were verified in the genome of Streptomyces sp. AMCC400023, and 58 unique toxicity-associated genes were found in S. scabiei 8722 genome, all of which were associated with secreted proteins, enzymes, etc. These results showed that there were certain differences in genetic composition between Streptomyces sp. AMCC400023 and S. scabiei 87-22. In addition, this analysis identified 69 common virulence-associated genes in the Streptomyces sp. AMCC400023 genome, most of which encoded proteins, such as putative secretory proteins, transcriptional regulators, membrane transporters, and enzymes involved in secondary metabolite biosynthesis, and the transcription of these genes might enhance pathogenicity.

In addition, the Streptomyces sp. AMCC400023 genome contained certain genes in the coronatine (COR) synthetic gene cluster that had been identified in S. scabiei. COR is a major virulence factor in the gram-negative plant pathogen Pseudomonas syringae, and it causes various symptoms in plant hosts, such as chlorosis, inhibition of root growth, and stimulation of ethylene synthesis (Bender et al. 1999; Bignell et al. 2010b). The Streptomyces sp. AMCC400023 genome also contained genes associated with the synthesis of the plant hormone indole-3-acetic acid (IAA), which indicated that the organism could produce IAA from L-tryptophan via the indole-3-acetamide pathway (McClerklin et al. 2018; Spaepen et al. 2007). Other than the two synthetic pathways above, the Streptomyces sp. AMCC400023 strain also contained cutinase and other enzymes that might be involved in successful infection of host plants. All of these data supported that Streptomyces sp. AMCC400023 was different from S. scabiei, and there was enough evidence to show that it was a distinct phytopathogen that causes potato common scab.

\section{DISCUSSION}

Streptomyces sp. AMCC400023 was isolated in our laboratory from infected potato scabs in Hebei Province, China. This strain was first identified as $S$. bottropensis based on morphological,

TABLE 4. Growth characteristics of Streptomyces sp. AMCC400023 on different mediums ${ }^{\mathrm{a}}$

\begin{tabular}{lccc}
\hline Medium & $\begin{array}{c}\text { Aerial } \\
\text { mycelia }\end{array}$ & $\begin{array}{c}\text { Substrate } \\
\text { mycelium }\end{array}$ & $\begin{array}{c}\text { Soluble } \\
\text { pigment }\end{array}$ \\
\hline Tryptone-yeast extraction (ISP 1) & $\mathrm{W}$ & $\mathrm{Y}$ & $\mathrm{No}$ \\
Yeast-malt extract agar (ISP 2) & $\mathrm{B}$ & $\mathrm{B}$ & $\mathrm{No}$ \\
Oat medium (ISP 3) & $\mathrm{G}$ & $\mathrm{YW}$ & No \\
Inorganic salt-starch agar (ISP 4) & $\mathrm{G}$ & $\mathrm{YG}$ & No \\
Glycerol-asparagine agar (ISP 5) & $\mathrm{B}$ & $\mathrm{B}$ & $\mathrm{Y}$ \\
Peptone-yeast extract iron agar (ISP 6) & $\mathrm{GW}$ & $\mathrm{LBB}$ & $\mathrm{B}$ \\
Tyrosine agar (ISP 7) & $\mathrm{YW}$ & $\mathrm{Y}$ & No \\
Nutrient agar & $\mathrm{W}$ & $\mathrm{W}$ & No \\
\hline
\end{tabular}

a B, brown; G, gray; GW, grayish white; ISP, International Streptomyces Project; LBB, light black brown; W, white; Y, yellow; YG, yellowish gray; and YW, yellowish white.
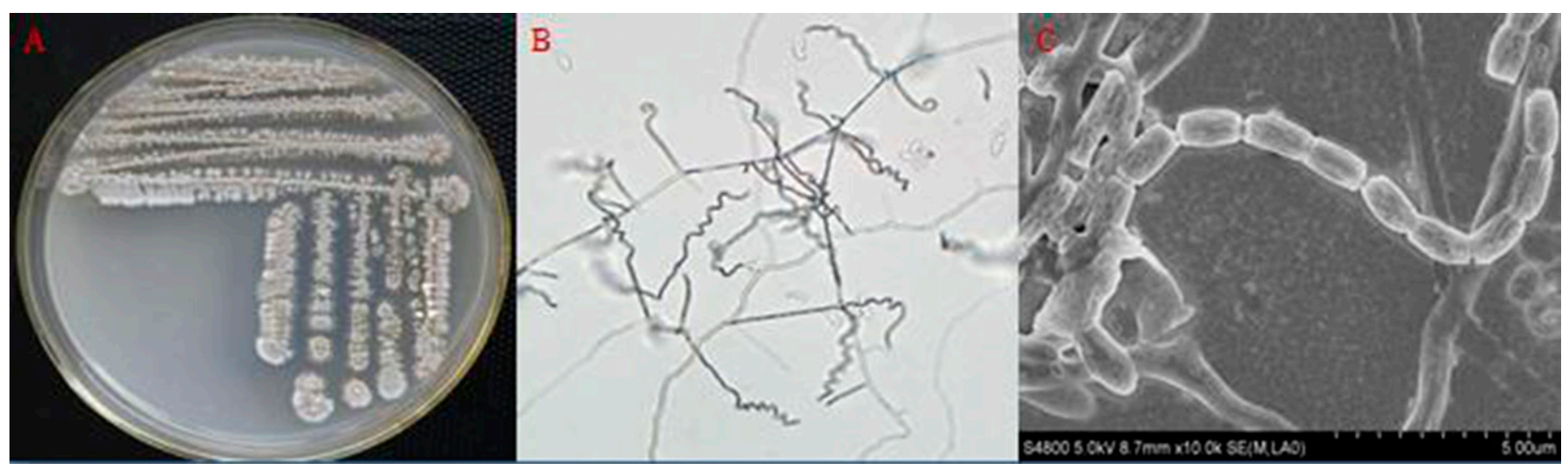

Fig. 3. Morphological characteristics of the strain Streptomyces sp. AMCC400023. A, Colony morphology on oat agar medium for 14 days. B, Microscopic morphology of aerial mycelium (400x). C, Spore-bearing mycelium under a scanning electron microscope. 
physiological, and biochemical characteristics as well as 16S rDNA analysis (Zhou et al. 2016). In this paper, after verifying the pathogenicity of Streptomyces sp. AMCC400023, systematic analyses, including morphological, physiological, and biochemical characterization; 16S rRNA gene analysis; and genomic ANI and isDDH analyses, were carried out. Compared with data from DDH analysis, isDDH data are reproducible and have direct utility (Goris et al. 2007), and ANI analysis is also provides a good estimate of evolutionary distance (Zhang and Qiu 2015, 2016; Zhang et al. 2016 b). In general, the ANI value $95 \%$, which is equivalent to the isDDH value $70 \%$, can be used for species identification (Goris et al. 2007). The complete genome analysis based on the NCBI database (Fig. 5) showed that Streptomyces sp. AMCC400023 was clustered with Streptomyces sp. 96-12, S. scabiei NRRL B-24093, and S. scabiei NRRL B-2801 in the phylogenetic tree, which was completely consistent with ANI and isDDH results (Fig. 9). According to a genome-wide phylogenetic tree and ANI and isDDH analysis, S. scabiei NRRL B-24093 and S. scabiei NRRL B-2801 were likely to be misidentified as S. scabiei. In fact, Streptomyces sp. AMCC400023, strain NRRL B-24093, and strain NRRL B-2801 were an independent species differing from S. scabiei under the genus Streptomyces. The spores formed by Streptomyces sp. AMCC400023 were gray and columnar, and the spore chains were loosely spiral. Rich in endophytic hyphae and aerial hyphae, the aerial hyphae were gray to white in different media, and the hyphae in the base were gray to yellow or yellowish brown. Soluble

TABLE 5. Comparison of physiological and biochemical characteristics between Streptomyces sp. AMCC400023 and related potato scab pathogens ${ }^{\mathrm{a}}$

\begin{tabular}{|c|c|c|c|c|c|c|c|}
\hline Characteristic index & AMCC400023 & S. scabiei & S. turgidiscabies & S. acidiscabies & S. caviscabies & S. stelliscabiei & S. europaeiscabiei \\
\hline Spore color & $\mathrm{G}$ & $\mathrm{G}$ & $\mathrm{G}$ & W & W & $\mathrm{G}$ & $\mathrm{G}$ \\
\hline Spore chain & $\mathrm{Sp}$ & $\mathrm{Sp}$ & $\mathrm{Rf}$ & $\mathrm{Rf}$ & $\mathrm{Rf}$ & $\mathrm{Sp}$ & $\mathrm{Sp}$ \\
\hline Melanin & + & + & - & - & - & + & + \\
\hline D-Fructose & - & + & + & + & - & + & + \\
\hline D-Glucose & + & + & & ND & ND & + & + \\
\hline D-Mannitol & + & + & + & + & - & + & + \\
\hline Raffinose & + & + & + & - & + & + & + \\
\hline Rhamnose & + & + & + & + & - & + & + \\
\hline Sucrose & + & + & + & + & - & + & + \\
\hline D-Xylose & + & + & + & + & - & + & + \\
\hline Inositol & + & + & + & + & ND & + & + \\
\hline L-Histidine & + & + & + & + & ND & ND & ND \\
\hline Methionine & + & + & + & + & + & ND & ND \\
\hline $\mathrm{pH} 4.0$ & - & - & - & + & ND & ND & ND \\
\hline $\mathrm{pH} 4.5$ & + & - & + & + & - & ND & ND \\
\hline pH 5.0 & + & + & + & + & ND & ND & ND \\
\hline $5.0 \% \mathrm{NaCl}$ & + & + & - & ND & ND & - & ND \\
\hline Crystal violet $(0.5 \mu \mathrm{g} / \mathrm{ml})$ & + & - & - & + & V & - & - \\
\hline Phenol $(0.1 \%)$ & + & - & - & + & + & ND & ND \\
\hline Penicillin (10 IU/ml) & + & - & + & + & + & + & + \\
\hline Streptomycin $(20 \mu \mathrm{g} / \mathrm{ml})$ & + & - & - & + & + & - & - \\
\hline
\end{tabular}

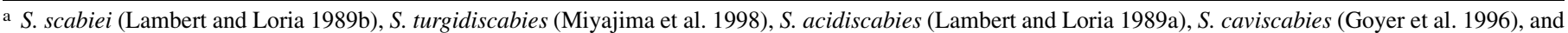
S. stelliscabiei and S. europaeiscabiei (Bouchek-Mechiche et al. 2000). A positive reaction is indicated by +, and a negative reaction is indicated by -. G, gray; ND, uncertain; Rf, straight flexible; Sp, spiral; V, according to strain differences; and W, white.

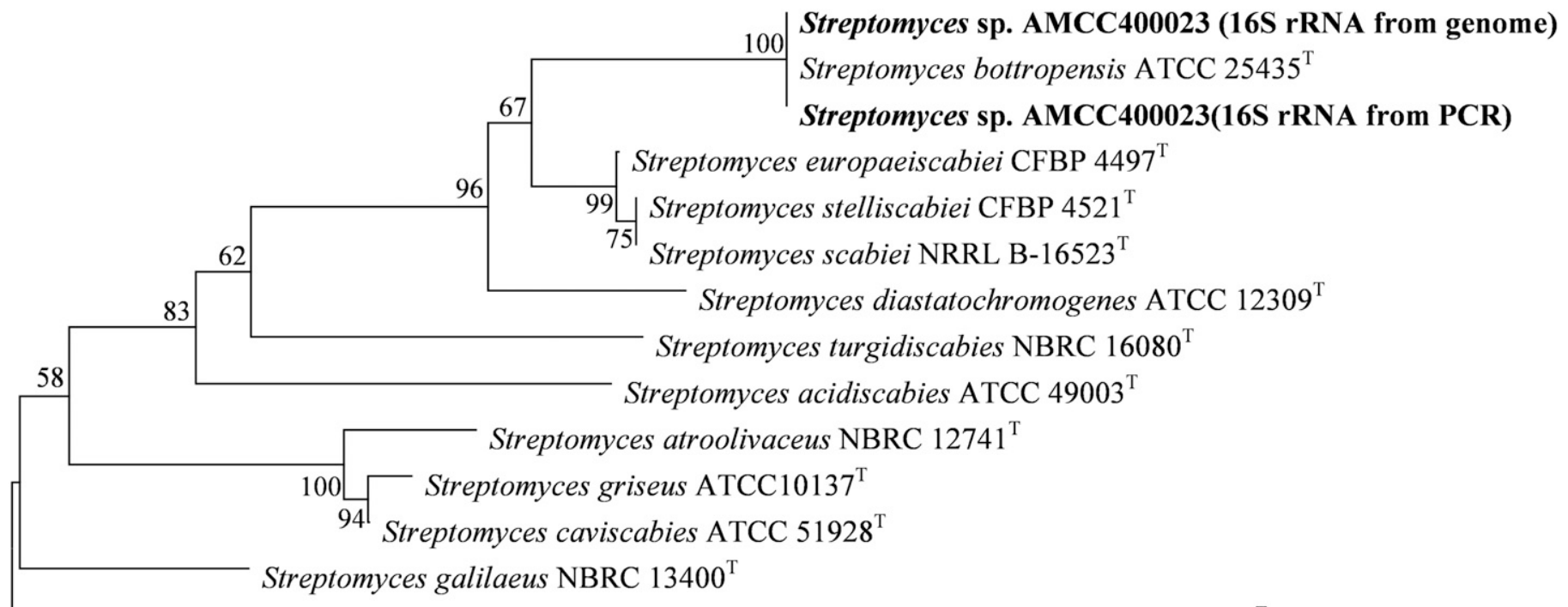

Streptomyces cinereus NBRC $12247^{\mathrm{T}}$

0.0050

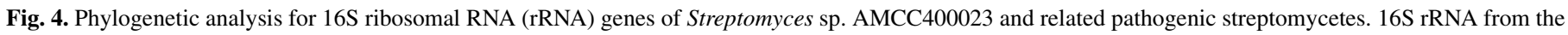

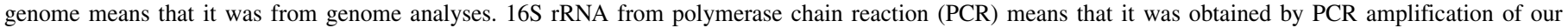
extracted DNA. 
pigments were produced on ISP 6 medium. As for the comparison of physiological and biochemical characteristics between Streptomyces sp. AMCC400023 and S. scabiei, test strain Streptomyces sp. AMCC400023 could utilize D-fructose, survive at $\mathrm{pH} 4.5$, and grow at crystal violet $(0.5 \mu \mathrm{g} / \mathrm{ml})$, phenol $(0.1 \%)$, penicillin $(10 \mathrm{IU} / \mathrm{ml})$, and streptomycin $(20 \mu \mathrm{g} / \mathrm{ml})$, all differed from $S$. scabiei. More important, there were certain differences in virulence-concerned genetic composition between Streptomyces sp. AMCC400023 and S. scabiei 87-22. The genome sequence of type strain S. scabiei NRRL B-16523 in NCBI could provide enough evidence to help us obtain the final identification results of Streptomyces sp. AMCC400023. Combining all of the analyses results above, we concluded that Streptomyces sp. AMCC400023 was a completely unique phytopathogenic species causing potato common scab. Of

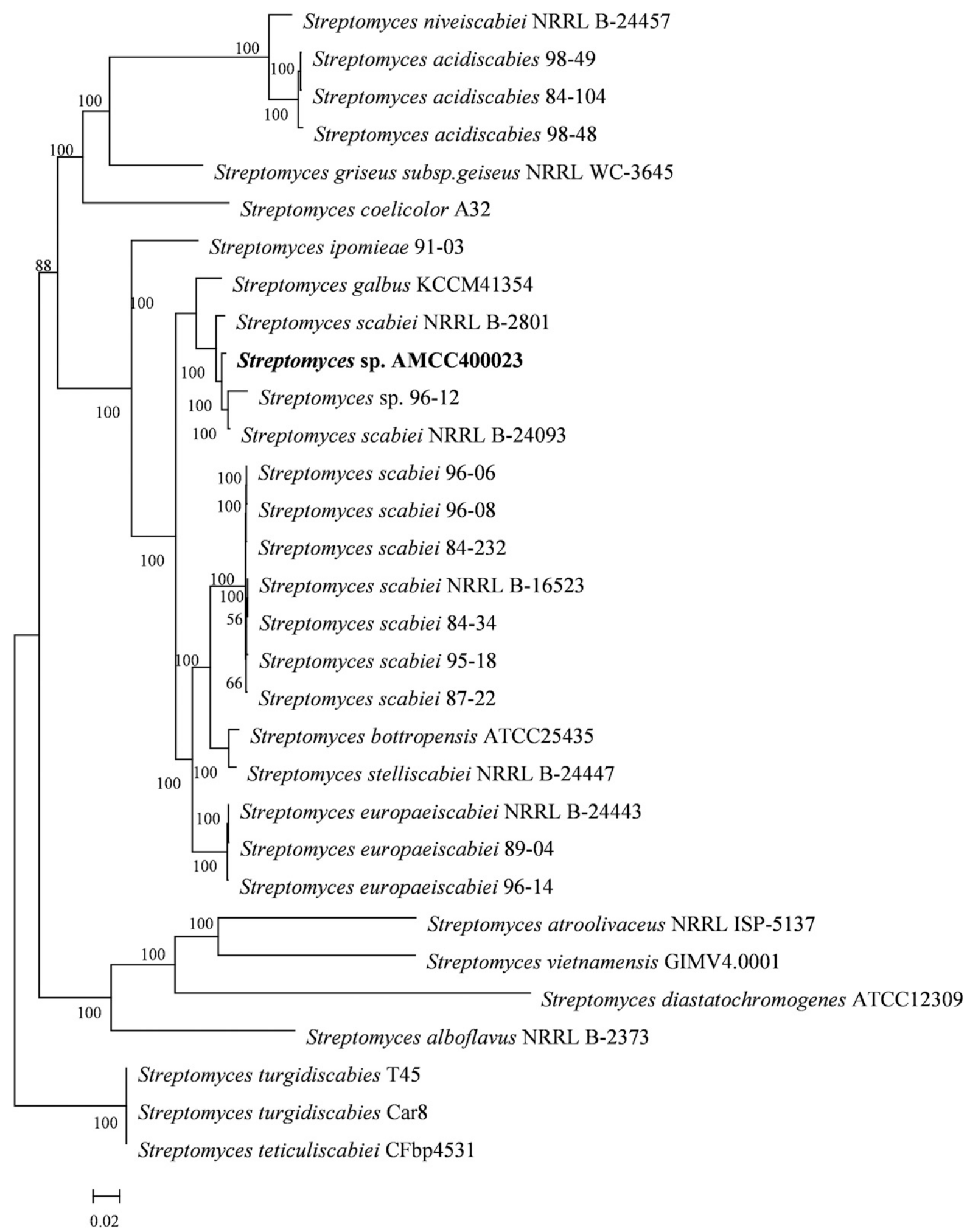

Fig. 5. Streptomyces phylogenetic tree among 31 Streptomyces species using the maximum likelihood algorithm RAxML based on the selection of 500 single-copy gene clusters in the Streptomyces genomes. A total of 1,000 bootstraps were calculated. The number above the branch is the percentage of the bootstrap value. 
all of the methods used for the identification of Streptomyces species, the genome-level data analyses were the most valuable and persuasive methods for Streptomyces species identification. Our result was consistent with the opinion that single-gene phylogenetic analysis does not solve the problems associated with streptomycete identification (Zhang et al. 2016a), and genome-based analysis tools could facilitate accurate identification of this unique genus (Auch et al. 2010; Richter and Rossellómóra 2009).

Currently, the development of sequencing technology has provided us with $>30$ genomic sequences of pathogenic Streptomyces strains (Zhang et al. 2016a). Simultaneously, the development of comparative genomics has helped accurately identify pathogenic factors from different pathogenic isolates. Zhang et al. (2016a) analyzed the PAI composition of some important pathogens, including not only different pathogenic isolates, but also different strains belonging to the same species (Zhang and Loria 2017; Zhang et al. 2016a). In this paper, the complete PAI composition of Streptomyces sp. AMCC400023 was identified, and the PAI was found to contain three genes encoding virulence factors, namely a ThxA synthetic gene cluster, necl, and tomA; the PAI of this strain was seen to be divided into two regions (TR and CR), where the TR included a ThxA synthetic gene cluster with the genes $t x t A, t x t B, t x t C, t x t D, t x t E, t x t H$, and $t x t R$. $t x t A$ and $t x t B$ encode nonribosomal peptide synthetases (NRPSs), $t x t C$ encodes a P450 monooxygenase, $t x t D$ encodes a nitric oxide synthase, and $t x t E$ encodes a cytochrome P450 enzyme responsible for tryptophan-specific nitrification (Bignell et al. 2014). $t x t R$ encodes an AraC family transcriptional regulator that regulates the synthesis of ThxA in vivo (Bignell et al. 2014; Joshi et al. 2007b). $t x t H$ encodes a short 65 -amino acid protein (Zhang et al. 2016a) that might belong to the MbtH-like protein family and play an important role in the regulation of NRPS activity (Herbst et al. 2013; Stegmann et al. 2006); however, the specific role of this protein in the synthesis of ThxA is unknown (Bignell et al. 2010a). The CR is made up of the necl and tomA genes. The main PAI composition of Streptomyces sp. AMCC400023 was very similar to that of S. scabiei and S. acidiscabies reported by Lerat et al. (2009).

However, there were differences in PAI composition among different pathogenic isolates and different strains of the same genus as described previously (Zhang and Loria 2017). For example, in $S$. turgidiscabies, the PAI also harbored the fas operon (HuguetTapia et al. 2011; Kers et al. 2005). S. acidiscabies isolates have three different types of PAI components, namely TR1 alone (84104), the complete TR element (a10), and no TR (98-48) (Zhang and Loria 2017). Chapleau et al. (2016) studied the mechanism for

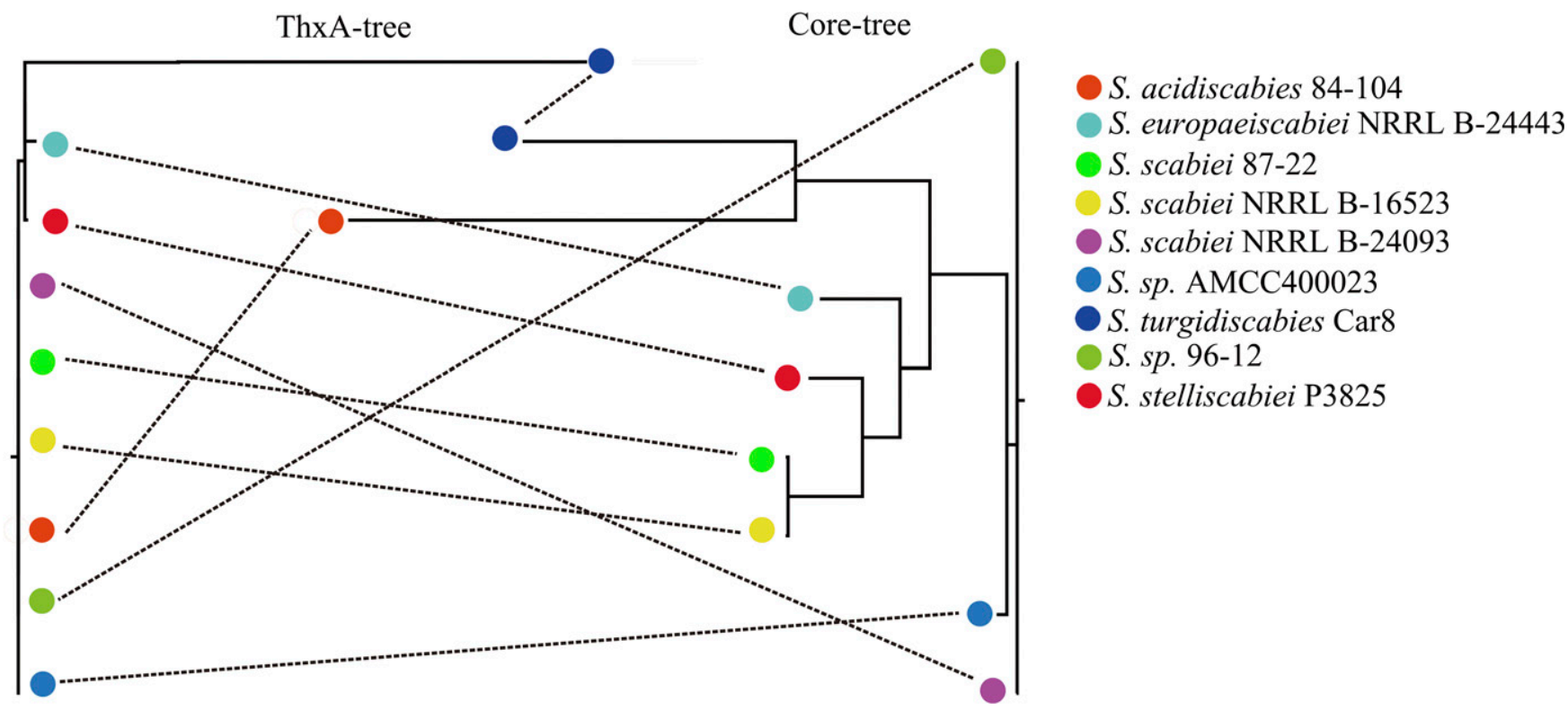

Fig. 6. Comparison of phylogenetic analysis of phytopathogens Streptomyces species. Core genomes tree (right) and thaxtomin A (ThxA) synthetic gene clusters tree (left).

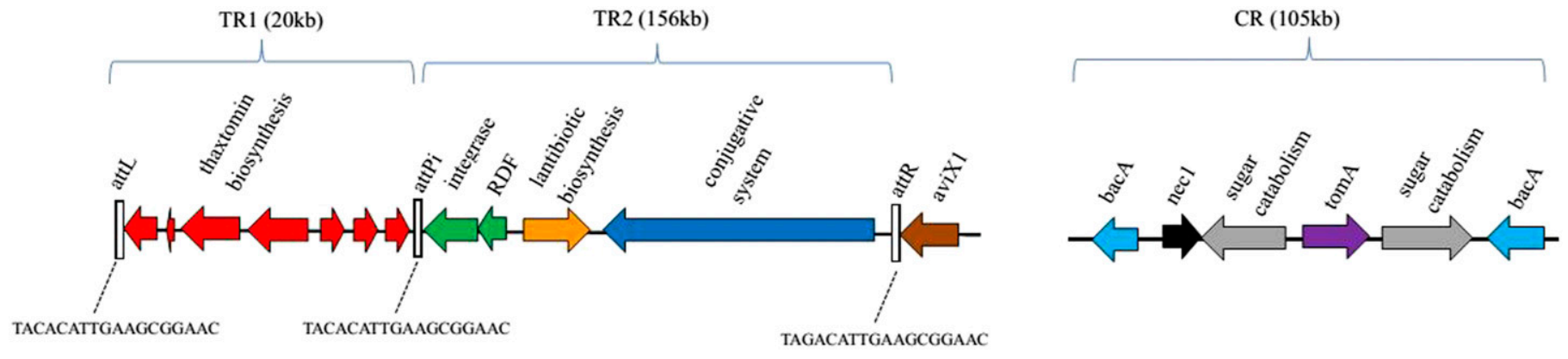

Fig. 7. Pathogenicity island gene structure map of Streptomyces sp. AMCC400023. The positions and directions of the open reading frames are shown by the arrows. The red arrows represent the thaxtomin synthetic genes, the green arrows represent the integrase and recombination directional factor (RDF), the orange arrow represents the lantibiotic synthesis genes, the blue arrow represents the conjugated integration genes, the brown arrow represents the aviX1 gene, the light blue arrows represent bacA genes, the black arrow represents the nec1 gene, the gray arrows represent the sugar metabolism genes, and the purple arrow represents the tomA gene. The att sites used to distinguish toxin region (TR; TR1 and TR2) are also shown. CR, colonization region. 
the excision and integration of TR, which involved three forms of mobilization: TR1 alone, TR2 alone, and the complete TR. Although the frequency of mobilization in the TR was very low, integration of the TR or TR2 alone could be detected in the recipient strain; however, TR1 could not be excised in the test strain that lacked TR2 (Chapleau et al. 2016). Zhang et al. (2016a) found that TR2 alone and the complete TR could be transferred to the soil saprophytic bacterium S. diastatochromogenes ATCC 12309; integration of the complete TR conferred a pathogenic phenotype to $S$. diastatochromogenes, whereas integration of TR2 alone did not (Zhang et al. 2016a). Subsequently, Zhang et al. (2016a) conducted a detailed analysis of the transfer of the TR, but in the entire study, no individual mobilization of TR1 was observed. This finding suggested that TR1 might be a cis-mobilization element that hijacked TR2 for conjugative integration, leading to HGT of pathogenic genes and the emergence of new pathogenic species (Zhang and Loria 2017).

Then, we performed a comparative genomic analysis of the PAI of Streptomyces sp. AMCC400023 and major scab-causing pathogens to construct a phylogenetic tree to reveal the PAI mobilization pathway in Streptomyces spp. Our ThxA phylogenetic analysis showed that the ThxA synthetic gene cluster of Streptomyces sp. AMCC400023 was highly similar to that of S. scabiei and S. acidiscabies and different from S. europaeiscabiei, especially $S$. turgidiscabies. Furthermore, the PAI gene composition of Streptomyces sp. AMCC400023 was similar to that of

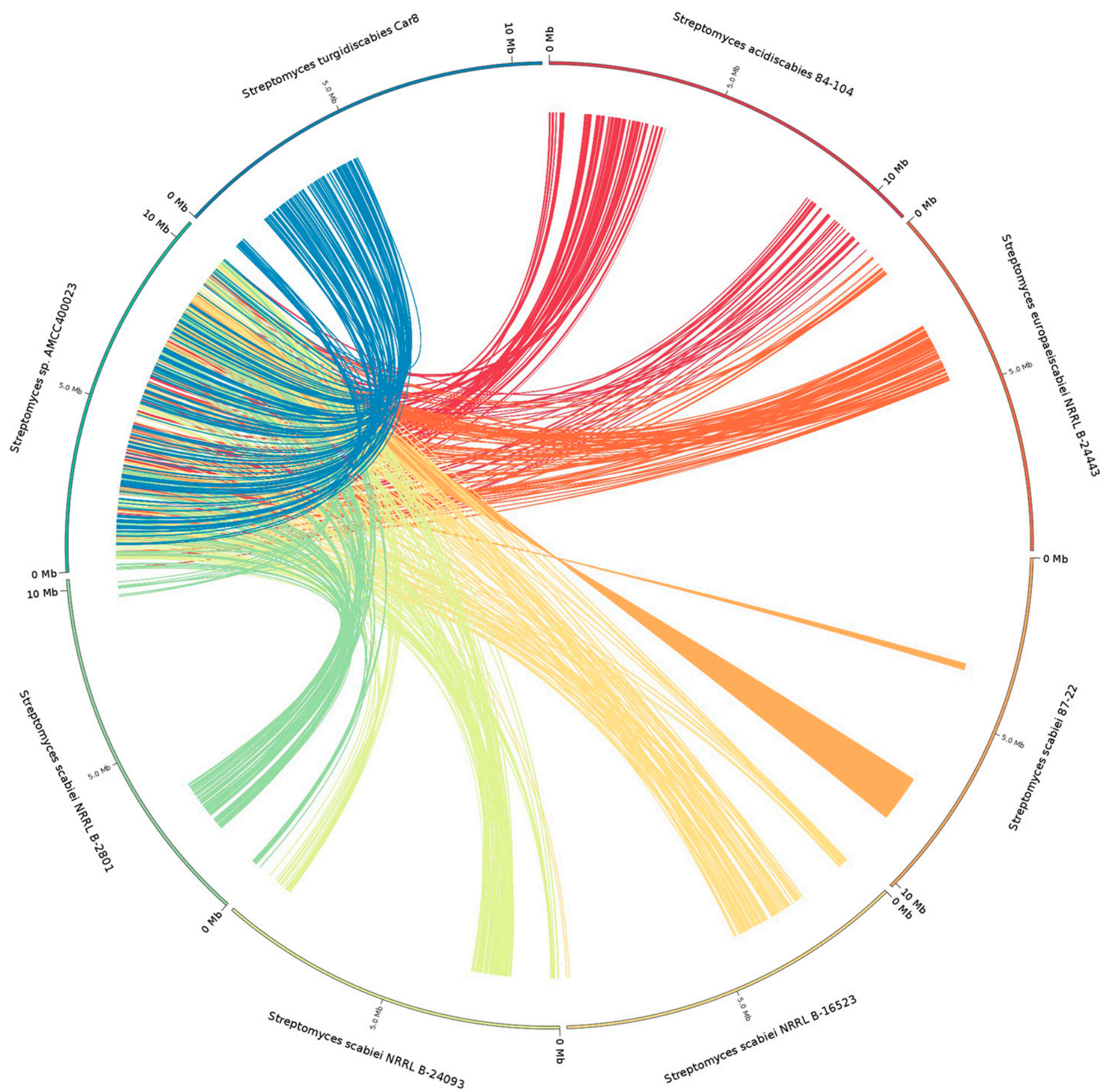

Fig. 8. Genome collinearity analysis of the main pathogenic Streptomyces genus. Green represents $S$. scabiei NRRL B-2801, light green represents $S$. scabiei NRRL B-24093, yellow represents S. scabiei NRRL B-16523, orange yellow represents S. scabiei 87-22, orange represents S. europaeiscabiei NRRL B-24443, red represents S. acidiscabies 84-104, blue represents S. turgidiscabies Car8, and grass green represents Streptomyces sp. AMCC400023. 
S. scabiei $87-22$, and only some individual genes were unique in our study. To further investigate the genetic composition and evolutionary pathway of PAI, a collinearity analysis of the genomes of the main pathogenic Streptomyces species was performed in this study. Collinearity analysis generally provides information regarding the genetic linkages between species. During mobilization and evolution of the PAIs of pathogenic Streptomyces species, some genes, such as the ThxA synthetic gene cluster and the necl and tomA genes, always maintained a linkage relationship, indicating that these genes had certain advantages during selection under certain conditions. This kind of finding provided useful clues for studying the evolution of PAIs. The results of the genomic collinearity analysis, shown in Figure 8, indicated that most genes in the genome of Streptomyces sp. AMCC400023 had homologous genes in the $S$. scabiei genomes, but there remained some genes that lacked corresponding homologous genes, indicating that there were some differences between the genomes of Streptomyces sp.
AMCC400023 and S. scabiei. This result was consistent with the results of the genome-wide phylogenetic analysis shown in Figure 5. In fact, the homologous genes between Streptomyces sp. AMCC400023 and S. scabiei 87-22 were so dense that we could confirm that, other than a very close relationship, there must be a gene transfer event behind between the two strains. After all, ancient S. scabiei was first found and studied in the scab pathogen history. In general, all of the results of the PAI composition analysis, ThxA phylogenetic analysis, genomic collinearity analysis, and ANI and isDDH analyses indicated that the PAI of Streptomyces sp. AMCC400023 might have been directly or indirectly acquired from S. scabiei by HGT.

Because of the availability of the whole-genome sequence of S. scabiei 87-22, Loria et al. (1997) performed a comparative genomic analysis using the $S$. scabiei 87-22 genome sequence, revealing the presence of a large number of toxicity-associated genes or gene clusters in S. scabiei (Bignell et al. 2010a). A majority of these genes

\begin{tabular}{|c|c|c|c|c|c|c|c|c|c|c|c|c|c|c|c|c|c|c|c|c|c|}
\hline $\begin{array}{l}=\mathrm{ANI} \geq 99 \% \\
\quad \text { and } \\
\text { isDDH } \geq 79 \% \\
=\mathrm{ANI} \geq 95 \% \text { and }<99 \% \\
\quad \text { and } \\
\text { isDDH } \geq 70 \% \text { and }<79 \%\end{array}$ & 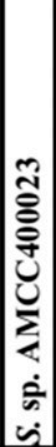 & 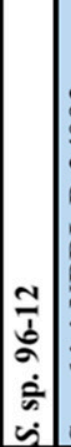 & 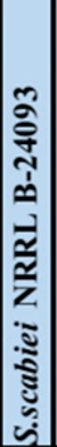 & 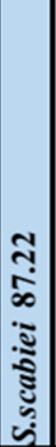 & 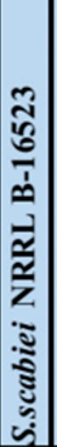 & 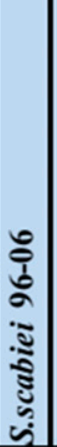 & 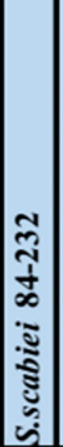 & 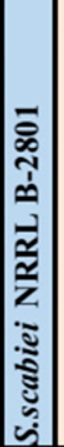 & 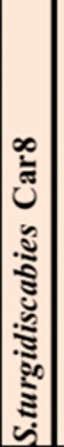 & 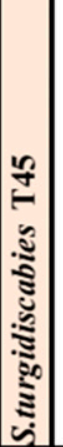 & 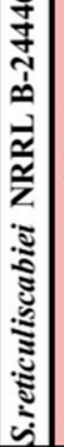 & 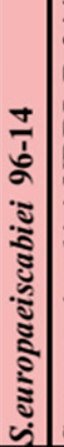 & 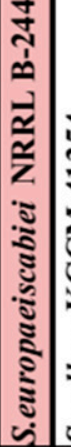 & 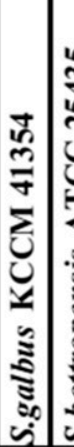 & 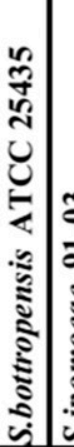 & 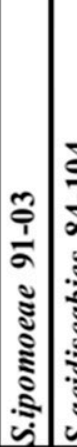 & 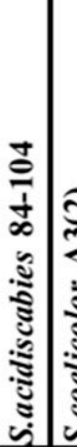 & (ָ) & 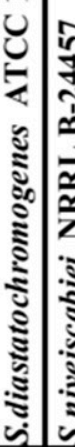 & 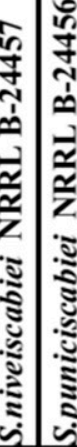 & $\begin{array}{l}3 \\
z \\
z \\
z \\
z\end{array}$ \\
\hline S. sp. AMCC400023 & & 83 & 83 & 37 & 37 & 38 & 38 & 72 & 26 & 26 & 25 & 38 & 38 & $46 \sqrt[3]{3}$ & 365 & \begin{tabular}{|l|l|}
31 & 2 \\
\end{tabular} & \begin{tabular}{l|l}
25 & 2 \\
\end{tabular} & \begin{tabular}{l|l}
25 & 2 \\
\end{tabular} & \begin{tabular}{l|l}
26 & 2 \\
\end{tabular} & \begin{tabular}{l|l}
25 & 25 \\
\end{tabular} & \begin{tabular}{|l|l}
5 & 3 \\
\end{tabular} \\
\hline S. sp. 96-12 & 99 & & 99 & 37 & 5 & 38 & 38 & 72 & 27 & \begin{tabular}{|l|l|}
26 & 0 \\
\end{tabular} & \begin{tabular}{|l|l|}
26 & 0 \\
\end{tabular} & \begin{tabular}{l|l|}
38 \\
\end{tabular} & \begin{tabular}{|l|l}
39 & 2 \\
\end{tabular} & \begin{tabular}{l|l}
48 & 3 \\
\end{tabular} & \begin{tabular}{l|l}
38 & 3 \\
\end{tabular} & \begin{tabular}{l|l}
32 & 2 \\
\end{tabular} & \begin{tabular}{l|l}
25 & 2 \\
\end{tabular} & \begin{tabular}{l|l}
26 & 2 \\
\end{tabular} & \begin{tabular}{l|l}
26 & 2 \\
\end{tabular} & \begin{tabular}{l|l}
25 & 26 \\
\end{tabular} & \begin{tabular}{l|l}
6 & 3 \\
\end{tabular} \\
\hline S.scabiei NRRL B-24093 & 99 & \begin{tabular}{|l|l|}
99 & 0 \\
\end{tabular} & & 37 & 4 & 38 & 38 & 72 & 26 & 26 & \begin{tabular}{|l|l|}
26 \\
\end{tabular} & 38 & \begin{tabular}{|l|l}
38 & 2 \\
\end{tabular} & \begin{tabular}{l|l}
48 & 3 \\
\end{tabular} & \begin{tabular}{l|l}
37 & 3 \\
\end{tabular} & \begin{tabular}{|l|l|}
32 & 2 \\
\end{tabular} & \begin{tabular}{l|l}
24 & 2 \\
\end{tabular} & \begin{tabular}{l|l}
26 & 2 \\
\end{tabular} & \begin{tabular}{l|l}
27 & 2 \\
\end{tabular} & \begin{tabular}{l|l}
25 & 26 \\
\end{tabular} & \begin{tabular}{l|l}
6 & 3 \\
\end{tabular} \\
\hline S.scabiei 87.22 & 88 & 89 & 89 & & 96 & 96 & 96 & 36 & 82 & 25 & 25 & \begin{tabular}{|l|l|}
39 & 0 \\
\end{tabular} & \begin{tabular}{|l|l}
39 & 3 \\
\end{tabular} & \begin{tabular}{l|l}
35 & 4 \\
\end{tabular} & \begin{tabular}{l|l}
43 & 3 \\
\end{tabular} & \begin{tabular}{|l|l|}
31 & 2 \\
\end{tabular} & \begin{tabular}{l|l}
25 & 2 \\
\end{tabular} & \begin{tabular}{l|l}
25 & 2 \\
\end{tabular} & \begin{tabular}{l|l}
26 & 2 \\
\end{tabular} & \begin{tabular}{l|l|}
25 & 25 \\
\end{tabular} & \begin{tabular}{|l|l}
5 & 4 \\
\end{tabular} \\
\hline S.scabiei NRRL B-16523 & 88 & \begin{tabular}{|l|l|}
89 \\
\end{tabular} & 89 & 99 & & 97 & 98 & \begin{tabular}{|l|l|}
2 & \\
\end{tabular} & 82 & \begin{tabular}{|l|l}
0 & \\
\end{tabular} & \begin{tabular}{l|l}
0 \\
\end{tabular} & 9. & \begin{tabular}{l|l}
40 & 3 \\
\end{tabular} & \begin{tabular}{l|l}
36 & 4 \\
\end{tabular} & 445 & \begin{tabular}{|l|l|}
31 & 2 \\
\end{tabular} & \begin{tabular}{l|l}
25 & 2 \\
\end{tabular} & \begin{tabular}{l|l}
25 & 0 \\
\end{tabular} & \begin{tabular}{l|l}
0 & 0 \\
\end{tabular} & \begin{tabular}{l|l}
0 & 0 \\
\end{tabular} & $\begin{array}{l}4 \\
\end{array}$ \\
\hline S.scabiei 96-06 & 89 & \begin{tabular}{|l|l|}
89 & \\
\end{tabular} & 89 & 99 & 99 & & 98 & 37 & 82 & \begin{tabular}{|l|l|}
27 & -1 \\
\end{tabular} & 82 & 41 & \begin{tabular}{|l|l}
41 & 3 \\
\end{tabular} & \begin{tabular}{|l|l}
37 & 4 \\
\end{tabular} & \begin{tabular}{l|l}
45 & 3 \\
\end{tabular} & \begin{tabular}{l|l}
32 & 2 \\
\end{tabular} & \begin{tabular}{l|l}
26 & 2 \\
\end{tabular} & \begin{tabular}{l|l}
26 & 2 \\
\end{tabular} & \begin{tabular}{l|l}
26 & 2 \\
\end{tabular} & \begin{tabular}{l|l}
25 & 26 \\
\end{tabular} & $\begin{array}{ll}6 & 4 \\
\end{array}$ \\
\hline S.scabiei 84-232 & 89 & 89 & 89 & 99 & 99 & 99 & & 37 & 82 & 26 & 82 & \begin{tabular}{|l|l|}
40 & \\
\end{tabular} & \begin{tabular}{l|l}
40 & 3 \\
\end{tabular} & \begin{tabular}{|l|l}
36 & 2 \\
\end{tabular} & \begin{tabular}{l|l}
44 & 3 \\
\end{tabular} & \begin{tabular}{|l|l|}
31 & 2 \\
\end{tabular} & \begin{tabular}{l|l}
25 & 2 \\
\end{tabular} & \begin{tabular}{l|l}
26 & 2 \\
\end{tabular} & \begin{tabular}{l|l}
26 & 2 \\
\end{tabular} & \begin{tabular}{l|l|}
25 & 25 \\
\end{tabular} & \begin{tabular}{l|l}
5 & 4 \\
\end{tabular} \\
\hline S.scabiei NRRL B-2801 & 96 & 96 & 96 & 88 & 88 & 88 & 88 & & 82 & 82 & 82 & \begin{tabular}{|l|l|}
89 & 0 \\
\end{tabular} & \begin{tabular}{l|l}
89 & 5 \\
\end{tabular} & \begin{tabular}{l|l}
92 & 8 \\
\end{tabular} & \begin{tabular}{l|l}
88 & 8 \\
\end{tabular} & \begin{tabular}{l|l}
86 & 8 \\
\end{tabular} & \begin{tabular}{l|l}
80 & 8 \\
\end{tabular} & \begin{tabular}{l|l}
81 & 2 \\
\end{tabular} & \begin{tabular}{l|l}
26 & 2 \\
\end{tabular} & \begin{tabular}{l|l}
25 & 26 \\
\end{tabular} & \begin{tabular}{l|l}
6 & 3 \\
\end{tabular} \\
\hline S.turgidiscabies Car8 & 82 & 82 & 82 & 26 & 26 & 27 & 27 & 26 & & 99 & 99 & 27 & \begin{tabular}{|l|l|l}
26 & 2 \\
\end{tabular} & \begin{tabular}{l|l}
25 & 2 \\
\end{tabular} & 255 & \begin{tabular}{|l|l|}
26 & 2 \\
\end{tabular} & \begin{tabular}{l|l}
24 & 2 \\
\end{tabular} & \begin{tabular}{l|l}
25 & 2 \\
\end{tabular} & \begin{tabular}{l|l}
26 & 2 \\
\end{tabular} & \begin{tabular}{l|l}
24 & 25 \\
\end{tabular} & $\begin{array}{ll}5 & 2 \\
\end{array}$ \\
\hline S.turgidiscabies $\mathrm{T} 45$ & 82 & \begin{tabular}{|l|}
82 \\
\end{tabular} & 82 & 82 & 82 & 82 & 82 & 26 & \begin{tabular}{|l|l|l|}
99 \\
\end{tabular} & 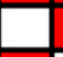 & 99 & 82 & \begin{tabular}{|l|l}
26 \\
\end{tabular} & \begin{tabular}{l|l}
25 & 2 \\
\end{tabular} & \begin{tabular}{l|l}
25 & 2 \\
\end{tabular} & \begin{tabular}{|l|l}
25 & 2 \\
\end{tabular} & 242 & \begin{tabular}{l|l}
24 & 2 \\
\end{tabular} & \begin{tabular}{l|l}
26 & 2 \\
\end{tabular} & \begin{tabular}{l|l|}
24 & 25 \\
\end{tabular} & \begin{tabular}{l|l}
5 & 2 \\
\end{tabular} \\
\hline S.reticuliscabiei NRRL B-24446 & 82 & \begin{tabular}{|l|l|}
82 \\
\end{tabular} & 82 & 81 & 82 & 26 & 26 & 26 & 99 & 99 & & 26 & \begin{tabular}{|l|l}
25 & 2 \\
\end{tabular} & \begin{tabular}{l|l}
25 & 2 \\
\end{tabular} & \begin{tabular}{l|l}
25 & 2 \\
\end{tabular} & \begin{tabular}{|l|l|}
26 & 2 \\
\end{tabular} & \begin{tabular}{l|l}
24 & 2 \\
\end{tabular} & \begin{tabular}{l|l}
25 & 2 \\
\end{tabular} & \begin{tabular}{l|l}
26 & 2 \\
\end{tabular} & \begin{tabular}{l|l}
24 & 25 \\
\end{tabular} & $\begin{array}{l}5 \\
5\end{array}$ \\
\hline S.europaeiscabiei 96-14 & 89 & 89 & 89 & 89 & 89 & 89 & 89 & 38 & 82 & 26 & 82 & & $95[3$ & \begin{tabular}{|l|l}
38 & 4 \\
\end{tabular} & \begin{tabular}{l|l}
42 & 3 \\
\end{tabular} & \begin{tabular}{|l|l|l}
32 & 2 \\
\end{tabular} & \begin{tabular}{l|l}
25 & 2 \\
\end{tabular} & \begin{tabular}{l|l}
25 & 2 \\
\end{tabular} & $27 \sqrt{27}$ & \begin{tabular}{l|l|l}
25 & 25 \\
\end{tabular} & \begin{tabular}{l|l}
5 & 4 \\
\end{tabular} \\
\hline S.europaeiscabiei NRRL B-24443 & 89 & 89 & 89 & 89 & 89 & 89 & 89 & 38 & 82 & 82 & 82 & \begin{tabular}{l|l}
99 \\
\end{tabular} & & 38 & \begin{tabular}{l|l}
42 & 3 \\
\end{tabular} & \begin{tabular}{|l|l|}
32 & 2 \\
\end{tabular} & \begin{tabular}{l|l}
25 & 2 \\
\end{tabular} & \begin{tabular}{l|l}
25 & 2 \\
\end{tabular} & \begin{tabular}{l|l}
26 & 2 \\
\end{tabular} & \begin{tabular}{l|l}
25 & 25 \\
\end{tabular} & $\begin{array}{ll}5 & 4 \\
\end{array}$ \\
\hline S.galbus KCCM 41354 & 92 & \begin{tabular}{|l|l}
92 \\
\end{tabular} & 92 & 88 & 88 & 88 & 88 & 48 & 81 & 81 & 82 & 89 & \begin{tabular}{|l|l|}
89 & 0 \\
\end{tabular} & & \begin{tabular}{l|l}
36 & 3 \\
\end{tabular} & \begin{tabular}{|l|l|l}
32 & 2 \\
\end{tabular} & \begin{tabular}{l|l}
24 & 2 \\
\end{tabular} & \begin{tabular}{l|l}
25 & 2 \\
\end{tabular} & \begin{tabular}{l|l}
26 & 2 \\
\end{tabular} & \begin{tabular}{l|l}
24 & 25 \\
\end{tabular} & $\begin{array}{ll}5 & 3 \\
\end{array}$ \\
\hline S.bottropensis ATCC 25435 & 88 & 89 & 89 & 91 & 91 & 91 & 91 & 37 & 82 & 82 & 82 & 90 & \begin{tabular}{|l|l|l}
91 & 8 \\
\end{tabular} & 88 & & \begin{tabular}{|l|l|}
31 & 2 \\
\end{tabular} & 2424 & \begin{tabular}{l|l}
25 & 2 \\
\end{tabular} & \begin{tabular}{l|l}
26 & 2 \\
\end{tabular} & \begin{tabular}{l|l|l}
24 & 25 \\
\end{tabular} & \begin{tabular}{l|l}
5 & 7 \\
\end{tabular} \\
\hline S.ipomoeae 91-03 & 85 & \begin{tabular}{|l|}
86 \\
\end{tabular} & 86 & 85 & 85 & 86 & 86 & 32 & 82 & 82 & 82 & 86 & \begin{tabular}{l|l}
86 & 8 \\
\end{tabular} & \begin{tabular}{|l|l|}
86 & \\
\end{tabular} & 85 & & \begin{tabular}{l|l}
25 & 2 \\
\end{tabular} & \begin{tabular}{l|l}
26 & 2 \\
\end{tabular} & \begin{tabular}{l|l}
27 & 2 \\
\end{tabular} & \begin{tabular}{l|l}
25 & 26 \\
\end{tabular} & $\begin{array}{ll}6 & 3 \\
\end{array}$ \\
\hline S.acidiscabies 84-104 & 80 & \begin{tabular}{|l|}
80 \\
\end{tabular} & 80 & 80 & 80 & 81 & 81 & 24 & 80 & 80 & 80 & 81 & \begin{tabular}{|l|l}
80 & 8 \\
\end{tabular} & \begin{tabular}{|l|l|}
80 & \\
\end{tabular} & \begin{tabular}{l|l}
80 & 8 \\
\end{tabular} & \begin{tabular}{l|l}
80 & \\
\end{tabular} & & 242 & \begin{tabular}{l|l}
24 & 5 \\
\end{tabular} & \begin{tabular}{l|l}
51 & 24 \\
\end{tabular} & $\begin{array}{l}42 \\
\end{array}$ \\
\hline S.coelicolor A3(2) & 81 & \begin{tabular}{|l|l}
82 \\
\end{tabular} & 81 & 81 & 81 & 82 & 82 & 26 & 81 & 81 & 81 & 81 & \begin{tabular}{|l|l}
81 & 8 \\
\end{tabular} & \begin{tabular}{|l|l}
81 & \\
\end{tabular} & \begin{tabular}{l|l}
81 & 8 \\
\end{tabular} & \begin{tabular}{|l|l|}
81 & 8 \\
\end{tabular} & \begin{tabular}{l|l}
80 & 0 \\
\end{tabular} & & 25 & \begin{tabular}{l|l}
25 & 26 \\
\end{tabular} & $\begin{array}{ll}6 & 2 .\end{array}$ \\
\hline S.diastatochromogenes ATCC 12309 & 82 & 82 & 82 & 81 & 85 & 82 & 82 & 82 & 82 & 82 & 82 & 82 & \begin{tabular}{|l|l|l}
82 & 8 \\
\end{tabular} & 82 & \begin{tabular}{l|l}
82 & 8 \\
\end{tabular} & \begin{tabular}{l|l}
82 & 8 \\
\end{tabular} & \begin{tabular}{l|l}
80 & 8 \\
\end{tabular} & \begin{tabular}{l|l}
81 & \\
\end{tabular} & & \begin{tabular}{l|l}
25 & 26 \\
\end{tabular} & $6 \longdiv { 2 }$ \\
\hline S.niveiscabiei NRRL B-24457 & 80 & 81 & 81 & 80 & 80 & 81 & 81 & 81 & 80 & 80 & 80 & 80 & \begin{tabular}{|l|l}
80 & 8 \\
\end{tabular} & 80 & 80 & \begin{tabular}{|l|l}
80 & 9 \\
\end{tabular} & \begin{tabular}{l|l}
93 & 8 \\
\end{tabular} & \begin{tabular}{l|l}
80 & 8 \\
\end{tabular} & \begin{tabular}{l|l}
80 & \\
\end{tabular} & 225 & $\begin{array}{ll}5 & 2 . \\
\end{array}$ \\
\hline S.puniciscabiei NRRL B-24456 & 81 & \begin{tabular}{|l|}
82 \\
\end{tabular} & 82 & 81 & 81 & 82 & 82 & 82 & 81 & 81 & 81 & \begin{tabular}{l|l}
81 & \\
\end{tabular} & \begin{tabular}{l|l}
81 & 8 \\
\end{tabular} & \begin{tabular}{|l|l|}
81 & \\
\end{tabular} & 81 & \begin{tabular}{l|l|l}
82 & 8 \\
\end{tabular} & \begin{tabular}{l|l}
80 & 8 \\
\end{tabular} & \begin{tabular}{l|l}
82 & 8 \\
\end{tabular} & \begin{tabular}{l|l}
82 & 8 \\
\end{tabular} & 81 & \\
\hline S.stelliscabiei NRRL B-24447 & 89 & \begin{tabular}{|l|l|}
89 & \\
\end{tabular} & 89 & 91 & 92 & 92 & 91 & 89 & 82 & 82 & \begin{tabular}{l|l|l}
82 & 0 \\
\end{tabular} & \begin{tabular}{l|l}
90 \\
\end{tabular} & \begin{tabular}{|c|c}
90 & 8 \\
\end{tabular} & 89 & \begin{tabular}{l|l}
96 \\
96
\end{tabular} & \begin{tabular}{l|l}
86 & 8 \\
\end{tabular} & \begin{tabular}{l|l}
80 & 8 \\
\end{tabular} & \begin{tabular}{l|l}
81 & 8 \\
\end{tabular} & \begin{tabular}{l|l}
82 & 8 \\
\end{tabular} & \begin{tabular}{l|l}
81 & 81 \\
\end{tabular} & \\
\hline
\end{tabular}

Fig. 9. The average nucleotide identity (ANI) and in silico DNA-DNA hybridization (isDDH) values of phytopathogenic and closely related nonpathogenic Streptomyces. The lower triangles display ANI values, and the upper triangles display isDDH values. The values that met the request of both ANI $\geq 99 \%$ and isDDH $\geq 79 \%$ are colored red, and the values among $95 \leq \mathrm{ANI}<99 \%$ and $70 \leq$ isDDH $<79 \%$ are colored orange. 
were not detectable in other pathogenic Streptomyces species, but they were associated with the pathogenicity of the strain or plant-microbe interactions. This finding suggested that the pathogenicity of S. scabiei strains might also involve multiple toxicity determinants (Bignell et al. 2010a). Based on the availability of Streptomyces genomic sequences in the NCBI database, Loria et al. (1997) also conducted a comparative genomic analysis to identify toxicity-related factors that did not exist on the PAI, such as the PR-1 and CFA cluster that was conserved in S. scabiei (Bignell et al. 2010a). Therefore, by comparative genomic analysis of the toxin-associated genes of S. scabiei 87-22 and Streptomyces sp. AMCC400023, a total of 147 toxicity-related genes were identified. In addition to 69 common genes, Streptomyces sp. AMCC400023 harbored 60 unique toxicity-associated genes, and S. scabiei $87-22$ had 58 unique toxicity-associated genes, indicating that, in addition to the PAI, the two strains also differed in their toxicity-associated gene compositions.

Based on the results of all of the genomic analyses described above, we concluded that Streptomyces sp. AMCC400023 was a distinct pathogenic species. The PAI of Streptomyces sp. AMCC400023 might have been acquired from S. scabiei, which was the most ancient pathogenic Streptomyces species causing common scab.

\section{LITERATURE CITED}

Abdel-Rahman, T. M. A., Khalil, M. S., Moussa, T. A. A., and Al-Qaysi, A. D. A. 2012. Identification and characterization of Streptomyces alkaliscabies sp. nov. J. Food Agric. Environ. 10:476-483.

Auch, A. F., Jan, M., Klenk, H. P., and Göker, M. 2010. Digital DNA-DNA hybridization for microbial species delineation by means of genome-togenome sequence comparison. Stand. Genomic Sci. 2:117-134.

Aziz, R. K., Daniela, B., Best, A. A., Matthew, D. J., Terrence, D., Edwards, R. A., Formsma, K., Gerdes, S., Glass, E. M., Kubal, M., Meyer, F., Olsen, G. J., Olson, R., Osterman, A. L., Overbeek, R. A., McNeil, L. K., Paarmann, D., Paczian, T., Parrello, B., Pusch, G. D., Reich, C., Stevens, R., Vassieva, O., Vonstein, V., Wilke, A., and Zagnitko, O. 2008. The RAST server: Rapid annotations using subsystems technology. BMC Genomics 9:75.

Bender, C. L., Alarcón-Chaidez, F., and Gross, D. C. 1999. Pseudomonas syringae phytotoxins: Mode of action, regulation, and biosynthesis by peptide and polyketide synthetases. Microbiol. Mol. Biol. Rev. 63:266-292.

Bentley, S. D., Chater, K. F., Cerdeñotárraga, A. M., Challis, G. L., Thomson, N. R., James, K. D., Harris, D. E., Quail, M. A., Kieser, H., Harper, D., Bateman, A., Brown, S., Chandra, G., Chen, C. W., Collins, M., Cronin, A., Fraser, A., Goble, A., Hidalgo, J., Hornsby, T., Howarth, S., Huang, C. H., Kieser, T., Larke, L., Murphy, L., Oliver, K., O’Neil, S., Rabbinowitsch, E., Rajandream, M. A., Rutherford, K., Rutter, S., Seeger, K., Saunders, D., Sharp, S., Squares, R., Squares, S., Taylor, K., Warren, T., Wietzorrek, A., Woodward, J., Barrell, B. G., Parkhill, J., and Hopwood, D. A. 2002. Complete genome sequence of the model actinomycete Streptomyces coelicolor A3(2). Nature 417:141-147.

Bérdy, J. 2005. Bioactive microbial metabolites. J. Antibiot. (Tokyo) 58:1-26.

Bertram, R., Schlicht, M., Mahr, K., Nothaft, H., Saier, M. H., Jr., and Titgemeyer, F. 2004. In silico and transcriptional analysis of carbohydrate uptake systems of Streptomyces coelicolor A3(2). J. Bacteriol. 186: 1362-1373.

Bignell, D. R. D., Fyans, J. K., and Cheng, Z. 2014. Phytotoxins produced by plant pathogenic Streptomyces species. J. Appl. Microbiol. 116:223-235.

Bignell, D. R. D., Huguettapia, J. C., Joshi, M. V., Pettis, G. S., and Loria, R. 2010a. What does it take to be a plant pathogen: Genomic insights from Streptomyces species. Antonie van Leeuwenhoek 98:179-194.

Bignell, D. R. D., Seipke, R. F., Huguet-Tapia, J. C., Chambers, A. H., Parry, R. J., and Loria, R. 2010b. Streptomyces scabies 87-22 contains a coronafacic acid-like biosynthetic cluster that contributes to plant-microbe interactions. Mol. Plant-Microbe Interact. 23:161-175.

Bordeleau, E., Ghinet, M. G., and Burrus, V. 2012. Diversity of integrating conjugative elements in actinobacteria. Mob. Genet. Elements 2:119-124.

Bouchek-Mechiche, K., Gardan, L., Normand, P., and Jouan, B. 2000. DNA relatedness among strains of streptomyces pathogenic to potato in france: Description of three new species, S. europaeiscabiei sp. nov. and S. stelliscabiei sp. nov. associated with common scab, and $S$. reticuliscabiei sp. nov. associated with netted scab. Int. J. Commun. Syst. 50:91-99.

Braun, S., Gevens, A., Charkowski, A., Allen, C., and Jansky, S. 2017. Potato common scab: A review of the causal pathogens, management practices, varietal resistance screening methods, and host resistance. Am. J. Potato Res. 94:283-296.
Bukhalid, R. A., Takeuchi, T., Labeda, D., and Loria, R. 2002. Horizontal transfer of the plant virulence gene, nec1, and flanking sequences among genetically distinct Streptomyces strains in the Diastatochromogenes cluster. Appl. Environ. Microbiol. 68:738-744.

Chapleau, M., Guertin, J. F., Farrokhi, A., Lerat, S., Burrus, V., and Beaulieu, C. 2016. Identification of genetic and environmental factors stimulating excision from Streptomyces scabiei chromosome of the toxicogenic region responsible for pathogenicity. Mol. Plant Pathol. 17:501-509.

Dees, M., Sletten, A., and Hermansen, A. 2013. Isolation and characterization of Streptomyces species from potato common scab lesions in Norway. Plant Pathol. 62:217-225.

Delcher, A. L., Phillippy, A., Carlton, J., and Salzberg, S. L. 2002. Fast algorithms for large-scale genome alignment and comparison. Nucleic Acids Res. 30:2478-2483.

Edgar, R. C. 2004a. Muscle: A multiple sequence alignment method with reduced time and space complexity. BMC Bioinformatics 5:113.

Edgar, R. C. 2004b. MUSCLE: Multiple sequence alignment with high accuracy and high throughput. Nucleic Acids Res. 32:1792-1797.

Edwards, U., Rogall, T., Blöcker, H., Emde, M., and Böttger, E. C. 1989. Isolation and direct complete nucleotide determination of entire genes. Characterization of a gene coding for 16s ribosomal RNA. Nucleic Acids Res. 17:7843-7853.

Eggers, C. H., Gray, C. M., Preisig, A. M., Glenn, D. M., Pereira, J., Ayers, R. W., Alshahrani, M., Acabbo, C., Becker, M. R., Bruenn, K. N., Cheunq, T., Jendras, T. M., Shepley, A. B., and Moeller, J. T. 2016. Phage-mediated horizontal gene transfer of both prophage and heterologous DNAby $\phi b b-1$, a bacteriophage of Borrelia burgdorferi. Pathog. Dis. 74:ftw107.

Goris, J., Konstantinidis, K. T., Klappenbach, J. A., Coenye, T., Vandamme, P., and Tiedje, J. M. 2007. DNA-DNA hybridization values and their relationship to whole-genome sequence similarities. Int. J. Syst. Evol. Microbiol. 57:81-91.

Goyer, C., Faucher, E., and Beaulieu, C. 1996. Streptomyces caviscabies sp. nov. from deep-pitted lesions in potatoes in Québec, Canada. Int. J. Syst. Bacteriol. 46:635-639.

Guo, Y., Zheng, W., Rong, X., and Huang, Y. 2008. A multilocus phylogeny of the Streptomyces griseus 16s rRNA gene clade: Use of multilocus sequence analysis for Streptomycete systematics. Int. J. Syst. Evol. Microbiol. 58: 149-159.

Hao, J. J., Meng, Q. X., Yin, J. F., and Kirk, W. W. 2009. Characterization of a new Streptomyces strain, DS3024, that causes potato common scab. Plant Dis. 93:1329-1334.

Healy, F. G., Wach, M., Krasnoff, S. B., Gibson, D. M., and Loria, R. 2000. The txtAB genes of the plant pathogen Streptomyces acidiscabies encode a peptide synthetase required for phytotoxin thaxtomin a production and pathogenicity. Mol. Microbiol. 38:794-804.

Herbst, D. A., Boll, B., Zocher, G., Stehle, T., and Heide, L. 2013. Structural basis of the interaction of Mbth-like proteins, putative regulators of nonribosomal peptide biosynthesis, with adenylating enzymes. J. Biol. Chem. 288:1991-2003.

Hodgson, D. A. 2000. Primary metabolism and its control in Streptomycetes: A most unusual group of bacteria. Adv. Microb. Physiol. 42:47-238.

Huguet-Tapia, J. C., Badger, J. H., Loria, R., and Pettis, G. S. 2011. Streptomyces turgidiscabies Car8 contains a modular pathogenicity island that shares virulence genes with other actinobacterial plant pathogens. Plasmid 65:118-124.

Huguet-Tapia, J. C., Bignell, D. R., and Loria, R. 2014. Characterization of the integration and modular excision of the integrative conjugative element paist in Streptomyces turgidiscabies Car8. PLoS One 9:e99345.

Johnson, E. G., Joshi, M. V., Gibson, D. M., and Loria, R. 2007. Cellooligosaccharides released from host plants induce pathogenicity in scabcausing Streptomyces, species. Physiol. Mol. Plant Pathol. 71:18-25.

Joshi, M., Rong, X., Moll, S., Kers, J., Franco, C., and Loria, R. 2007a. Streptomyces turgidiscabies secretes a novel virulence protein, nec1, which facilitates infection. Mol. Plant-Microbe Interact. 20:599-608.

Joshi, M. V., Bignell, D. R. D., Johnson, E. G., Sparks, J. P., Gibson, D. M., and Loria, R. 2007b. The Arac/Xyls regulator txtR modulates thaxtomin biosynthesis and virulence in Streptomyces scabies. Mol. Microbiol. 66: 633-642.

Joshi, M. V., and Loria, R. 2007. Streptomyces turgidiscabies possesses a functional cytokinin biosynthetic pathway and produces leafy galls. Mol. Plant-Microbe Interact. 20:751-758.

Kers, J. A., Cameron, K. D., Joshi, M. V., Bukhalid, R. A., Morello, J. E., Wach, M. J., Gibson, D. M., and Loria, R. 2005. A large, mobile pathogenicity island confers plant pathogenicity on Streptomyces species. Mol. Microbiol. 55:1025-1033.

King, R. R., and Lawrence, C. H. 1994. Isolation and characterization of thaxtomin-type phytotoxins associated wtih Streptomyces ipomoeae. J. Agric. Food Chem. 42:1791-1794. 
King, R. R., Lawrence, C. H., Clark, M. C., and Calhoun, L. A. 1989. Isolation and characterization of phytotoxins associated with Streptomyces scabies. J. Chem. Soc. Chem. Commun. 13:849-850.

Kreuze, J. F., Suomalainen, S., Paulin, L., and Valkonen, J. P. 1999. Phylogenetic analysis of 16s rRNA genes and PCR analysis of the nec1 gene from Streptomyces spp. causing common scab, pitted scab, and netted scab in Finland. Phytopathology 89:462.

Labeda, D. P., Goodfellow, M., Brown, R., Ward, A. C., Lanoot, B., Vanncanneyt, M., Swings, J., Kim, S. B., Liu, Z., Chun, J., Tamura, T., Oquchi, A., Kikuchi, H., Nishii, T., Tsuji, K., Yamaguchi, Y., Tase, A., Takahashi, M., Sakane, T., Suzuki, K. I., and Hatano, K. 2012. Phylogenetic study of the species within the family Streptomycetaceae. Antonie van Leeuwenhoek 101:73-104.

Lambert, D. H., and Loria, R. 1989a. Streptomyces acidiscabies sp. nov. Int. J. Syst. Bacteriol. 39:393-396.

Lambert, D. H., and Loria, R. 1989b. Streptomyces scabies sp. nov. nom. rev. Int. J. Syst. Bacteriol. 39:387-392.

Lawrence, C. H., Clark, M. C., and King, R. R. 1990. Induction of common scab symptoms in aseptically cultured potato tubers by the vivotoxin, thaxtomin. Phytopathology 80:606-608.

Leclerc, C., Zebré, A., Enault, J., Racine, P. J., and Leblanc, S. 2017. Evaluation of Streptomyces common scab toxins diffusion in potato tubers and through the intestinal barrier. Int. J. Curr. Microbiol. Appl. Sci. 6:1662-1676.

Leiminger, J., Frank, M., Wenk, C., Poschenrieder, G., Kellermann, A., and Schwarzfischer, A. 2013. Distribution and characterization of streptomyces species causing potato common scab in Germany. Plant Pathol. 62:611-623.

Leiner, R. H., Fry, B. A., Carling, D. E., and Loria, R. 1996. Probable involvement of thaxtomin a in pathogenicity of Streptomyces scabies on seedlings. Phytopathology 86:709-713.

Lerat, S., Simaobeaunoir, A. M., and Beaulieu, C. 2009. Genetic and physiological determinants of Streptomyces scabies pathogenicity. Mol. Plant Pathol. 10:579-585.

Li, L., Stoeckert, C. J., and Roos, D. S. 2003. Orthomcl: Identification of ortholog groups for eukaryotic Gnomes. Genome Res. 13:2178-2189.

Loria, R., Bignell, D. R., Huguet-Tapia, J. C., Joshi, M. V., Johnson, E. G., Seipke, R. F., and Gibson, D. M. 2008. Thaxtomin biosynthesis: The path to plant pathogenicity in the genus Streptomyces. Antonie van Leeuwenhoek 94:3-10.

Loria, R., Bukhalid, R. A., Creath, R. A., Leiner, R. H., Olivier, M., and Steffens, J. C. 1995. Differential production of thaxtomins by pathogenic Streptomyces species in vitro. Phytopathology 85:537-541.

Loria, R., Bukhalid, R. A., Fry, B. A., and King, R. R. 1997. Plant pathogenicity in the genus Streptomyces. Plant Dis. 81:836-846.

Loria, R., Kers, J., and Joshi, M. 2006. Evolution of plant pathogenicity in Streptomyces. Annu. Rev. Phytopathol. 44:469-487.

McClerklin, S. A., Lee, S. G., Harper, C. P., Nwumeh, R., Jez, J. M., and Kunkel, B. N. 2018. Indole-3-acetaldehyde dehydrogenase-dependent auxin synthesis contributes to virulence of Pseudomonas syringae strain DC3000. PLoS Pathog 14:e1006811.

Meier-Kolthoff, J. P., Auch, A. F., Klenk, H. P., and Göker, M. 2013. Genome sequence-based species delimitation with confidence intervals and improved distance functions. BMC Bioinformatics 14:60.

Miyajima, K., Tanaka, F., Takeuchi, T., and Kuninaga, S. 1998. Streptomyces turgidiscabies sp. nov. Int. J. Syst. Bacteriol. 48:495-502.

Park, D. H., Kim, J. S., Kwon, S. W., Wilson, C., Yu, Y. M., Hur, J. H., and Lim, C. K. 2003. Streptomyces luridiscabiei sp. nov. Streptomyces puniciscabiei $\mathrm{sp}$. nov. and Streptomyces niveiscabiei sp. nov. which cause potato common scab disease in Korea. Int. J. Syst. Evol. Microbiol. 53:2049-2054.
Pertry, I., Václavíková, K., Gemrotová, M., Spíchal, L., Galuszka, P., Depuydt, S., Temmerman, W., Stes, E., Dekeyser, A., Riefler, M., Biondi, S., Novák, O., Schmüllinq, T., Strnad, M., Tarkowski, P., Holsters, M., and Vereecke, D. 2010. Rhodococcus fascians impacts plant development through the dynamic fas-mediated production of a cytokinin mix. Mol. Plant-Microbe Interact. 23:1164-1174.

Punta, M., Coggill, P. C., Eberhardt, R. Y., Mistry, J., Tate, J., Boursnell, C., Pang, N., Forslund, K., Ceric, G., Clements, J., Heger, A., Holm, L., Sonnhammer, E. L. L., Eddy, S. R., Bateman, A., and Finn, R. D. 2011. The Pfam protein families database. Nucleic Acids Res. D290-D301.

Richter, M., and Rossellómóra, R. 2009. Shifting the genomic gold standard for the prokaryotic species definition. Proc. Natl. Acad. Sci. USA 106: 19126-19131.

Seipke, R. F., and Loria, R. 2008. Streptomyces scabies 87-22 possesses a functional tomatinase. J. Bacteriol. 190:7684-7692.

Shirling, E. B., and Gottlieb, D. 1966. Methods for characterization of Streptomyces species. Int. J. Syst. Bacteriol. 16:313-340.

Song, J., Lee, S. C., Kang, J. W., Baek, H. J., and Suh, J. W. 2004. Phylogenetic analysis of Streptomyces spp. isolated from potato scab lesions in Korea on the basis of 16S rRNA gene and 16S-23S rDNA internally transcribed spacer sequences. Int. J. Syst. Evol. Microbiol. 54:203-209.

Spaepen, S., Vanderleyden, J., and Remans, R. 2007. Indole-3-acetic acid in microbial and microorganism-plant signaling. FEMS Microbiol. Rev. 31: 425-448.

Stamatakis, A. 2014. RaxmL version 8: A tool for phylogenetic analysis and post-analysis of large phylogenies. Bioinformatics 30:1312-1313.

Stegmann, E., Rausch, C., Stockert, S., Burkert, D., and Wohlleben, W. 2006. The small Mbth-like protein encoded by an internal gene of the balhimycin biosynthetic gene cluster is not required for glycopeptide production. FEMS Microbiol. Lett. 262:85-92.

Wach, M. J., Krasnoff, S. B., Loria, R., and Gibson, D. M. 2007. Effect of carbohydrates on the production of thaxtomin A by Streptomyces acidiscabies. Arch. Microbiol. 188:81-88.

Wang, Y., Tang, H., Debarry, J. D., Tan, X., Li, J., Wang, X., Lee, T., Jin, H., Marler, B., Guo, H., Kissinger, J. C., and Paterson, A. H. 2012. Mcscanx: A toolkit for detection and evolutionary analysis of gene synteny and collinearity. Nucleic Acids Res. 40:e49.

Wanner, L. A. 2006. A survey of genetic variation in Streptomyces isolates causing potato common scab in the United States. Phytopathology 96: 1363-1371.

Zhang, Y., Bignell, D. R., Zuo, R., Fan, Q., Huguet-Tapia, J. C., Ding, Y., and Loria, R. 2016a. Promiscuous pathogenicity islands and phylogeny of pathogenic Streptomyces spp. Mol. Plant-Microbe Interact. 29:640-650.

Zhang, Y., Fan, Q., and Loria, R. 2016b. A re-evaluation of the taxonomy of phytopathogenic genera Dickeya and Pectobacterium using whole-genome sequencing data. Syst. Appl. Microbiol. 39:252-259.

Zhang, Y., and Loria, R. 2017. Emergence of novel pathogenic Streptomyces species by site-specific accretion and cis-mobilization of pathogenicity islands. Mol. Plant-Microbe Interact. 30:72-82.

Zhang, Y., and Qiu, S. 2015. Examining phylogenetic relationships of Erwinia, and Pantoea, species using whole genome sequence data. Antonie van Leeuwenhoek 108:1037-1046.

Zhang, Y., and Qiu, S. 2016. Phylogenomic analysis of the genus Ralstonia based on 686 single-copy genes. Antonie van Leeuwenhoek 109:71-82.

Zhou, B., Zhang, M. S., and Ma, X. K. 2016. First report of Streptomyces bottropensis causing potato common scab in Hebei province, China. Plant Dis. 101. 